\title{
Games Parents and Adolescents Play: Risky Behaviors, Parental Reputation, and Strategic Transfers
}

\author{
Lingxin Hao, \\ John Hopkins University
}

V. Joseph Hotz, and

UCLA, NBER and the California Center for Population Research

\section{Ginger Z. Jin}

University of Maryland and NBER

\begin{abstract}
This paper examines parental reputation formation in intra-familial interactions. In a repeated twostage game, children decide whether to drop out of high school or daughters decide whether to have births as teens and parents then decide whether to provide support to their children beyond age 18. Drawing on Milgrom and Roberts (1982) and Kreps and Wilson (1982), we show that, under certain conditions, parents have the incentive to penalize older children for their adolescent risk-taking behaviours in order to dissuade their younger children from such behaviours when reaching adolescence. We find evidence in favour of this parental reputation model.
\end{abstract}

\begin{abstract}
A significant percentage of adolescents engage in risky behaviours. For example, among US students enrolled in grades 9-12 in 2001, 47.1\% drank alcohol, 23.9\% used marijuana, and $45.6 \%$ had ever had sexual intercourse. 1 Some of this behaviour is a relatively benign element of the transition from youth to adulthood through which youth seek to establish their identity and independence from parents. But some of this experimentation can become excessive and have harmful long-run consequences. Consider, for example, teens engaging in unprotected sex. This behaviour results in about 3 million new cases of sexually transmitted diseases (STDs) each year2 and entails substantial medical and public health costs.3 Unprotected sex and/or use of ineffective contraceptive methods also led to 453,725 births to women under the age of 20 in 2001,4 of which $79 \%$ were out-of-wedlock.

Numerous studies suggest that early childbearing is associated with adverse consequences for both teen mothers and her children.5
\end{abstract}

Why do adolescents engage in risk-taking behaviours even if society, and presumably parents, disapproves of such behaviours? The answer to this question is important for improving our understanding of the causes of adolescent risky behaviours and, thus, for identifying effective methods to curb them. To address this question, many researchers focus on either the adolescents' decision-making process (O'Donoghue and Rabin 2001) or the influence of external forces, such as peer groups, mass media, school education, community

\footnotetext{
${ }^{1}$ Tabulations from the 2001 Youth Risk Behaviour Survey (YRBS). Centers for Disease Control and Prevention.

${ }^{2}$ Eng and Butler (1997).

${ }^{3}$ Chesson, et al. (2004) estimate that the direct medical costs of the 9 million new cases of STDs that occurred among adolescents and young adults in the US in 2001 cost $\$ 6.5$ billion.

${ }^{4}$ Child Trends (2003).

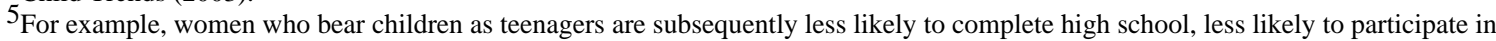
the labour force, more likely to have low earnings, and less likely to marry than are women who do not have children as teenagers. As a result, adolescent mothers and their children are likely to spend a substantial fraction of their lifetimes in poverty (see Upchurch and McCarthy 1990).
} 
organizations, and social policies. The role of parents in influencing such behaviours, i.e., parental control and monitoring of the risk-taking behaviour of their adolescents, has been a major focus of the psychological literature on adolescent risk-taking behaviour.6 Economic models of the family, especially those first developed by Becker $(1974,1991)$, examine how altruistic heads of families can influence the behaviour of their children, although this work does not explicitly consider how parents might deal with risk-taking behaviours of children. In this paper, we develop a new economic theory that focuses on the intra-familial interaction between parents and adolescent children and present empirical evidence on its validity.

Consider altruistic parents and a selfish teenage child engaged in a two-stage game. In the first stage, the adolescent decides whether to engage in risky behaviours. In the second stage, the parents decide whether to punish such behaviours by withholding resources to the child. According to Becker's Rotten Kid Theorem (Becker, 1974, 1991), altruistic parents can devise a set of resource transfers to ensure that the selfish child acts in a way that maximizes the welfare of the entire family. As Bergstrom (1989) points out, this game need not reach the desirable outcome (i.e. no risk-taking by adolescent children) that the Rotten Kid Theorem predicts if the preferences of parents and their child are not characterized by transferable utility, i.e., parents and their child differ in the valuations of money income. In the latter case, altruistic parents may not be willing to withhold transfers if their child engages in risky behaviours, even though the parents do not approve of such behaviours. The child foresees the (altruistic) parents' unwillingness to pre-commit to punishing his risktaking behaviour and, therefore, undertakes such behaviours in defiance of his parents' preferences. This equilibrium outcome implies that the altruistic parents do not achieve what is "best for the family" and may have little or no control over the behaviours of their adolescent children.

This paper provides a much more optimistic conclusion about the potential role of parents in influencing adolescent behaviour, even in the absence of transferable utility. In particular, we argue that the altruistic parents in the game described above may be able to use financial transfers to influence the risk-taking behaviour of adolescent children by exploiting their children's uncertainty about their family's preferences. Specifically, we model parentadolescent actions as a repeated game. Each round of the game has the same two stage structure as described above, characterizing parents' interactions with one child who has reached adolescence. Each child plays the game once, by birth order, whereas the parents play through all the rounds of the game. Initially, older children are uncertain as to the nature of the parents' preferences with respect to their engaging in risky behaviour, although the younger children in the family can learn from older siblings' experience about their parents' preferences. Drawing on the reputation model of Milgrom and Roberts (1982) and Kreps and Wilson (1982), we show that all parents, including the very altruistic, have incentives to penalize older children for their risky behaviours in order to dissuade their younger ones from engaging in such behaviours.

This reputation model of parent-child interactions yields two empirical predictions. First, parents with two or more children should be more willing to punish their older children who engage in risky behaviours in order to influence the actions of their later-born children.

Second, to the extent that parents can establish such reputations, their older children are less likely to engage in risky behaviours as teens. In essence, the reputation model implies that risk-taking of adolescent offspring and parental responses to such behaviours vary systematically by birth order.

\footnotetext{
${ }^{6}$ See Steinberg (2001) for a survey of this literature.
} 
Using data from the National Longitudinal Survey of Youth, 1979 Cohort (NLSY79), we analyze the outcomes of two types of risky behaviours among adolescents-teenage childbearing and dropping out of high school. Both behaviours appear to have long-term negative consequences. Teenage mothers are less successful in the labour and marriage markets7 and are more likely to expose their children to poverty later in life than women who do not have teen births. 8 Similarly, most children who drop out of school do not end up ever receiving a regular high school diploma and, as Cameron and Heckman (1993) find, high school dropouts have significantly lower earnings and levels of attainment later in life than do those who complete high school.9

Consistent with the reputation model, we find that daughters who had teen births or children who drop out of high school receive fewer parental transfers after reaching adulthood when the parent has a larger number of younger children in the family. Moreover, focusing on the offspring within the same family, we find that older siblings are less likely than younger ones to drop out of high school or to have births as teens. These findings are consistent with the reputation model's implications that parents may have an incentive to engage in strategic responses to the risk-taking behaviour of their children according to birth order and that older children understand these incentives and are more likely to respond by refraining from committing risky behaviours compared to their younger siblings.

We also consider two alternative explanations for systematic birth order differences in adolescent risk-taking behaviour and how parental transfers respond to it. One alternative is a variant of the "resource dilution" explanation for birth order differences in parental investments in their children. In particular, parental resources that could be used to influence their offspring's risk-taking behaviour are most constrained, or diluted, early in the parents' life cycle, but improve over time, either because parents' income increases and/or their children become adults and are no longer the parents' financial responsibility. As a result, parents have more resources later in life to reward their younger offspring for foregoing risky behaviours than they have for their oldest children. As we discuss below, such a model can generate birth order effects for families whose financial constraints change over the parents' life cycle, but not for families that are never financially constrained. In contrast, the reputation model implies that families that are not financially constrained should also exhibit birth order differences in the risk-taking behaviours of adolescent children and in parental transfer responses their behaviour. We exploit this difference in predicted effects by family financial status to distinguish between the two theories in the empirical analysis presented below.

We also explore whether the systematic differences in parental transfer and risk-taking behaviour by birth order are the result of parents learning about the consequences of such behaviour from rearing the first child. In particular, risk adverse parents may be strict in dealing with the risk-taking behaviour for the first child, but, as they learn about such behaviour and how to deal with it, they may become more lenient toward later-born children. We formalize this "parental learning" notion and systematically develop its testable implications. We find little support for this explanation of the systematic differences in parental transfer and risk-taking behaviour by birth order.

\footnotetext{
${ }^{7}$ While the evidence on the long-term consequences of teenage childbearing are controversial—see Hotz, McElroy and Sanders (2005) for example - such women do experience reductions in earnings and marriages prospects early in their adult lives.

${ }^{8}$ While giving up births for adoption might mitigate some of these adverse consequences, most teen mothers do not do so. Between 1989 and 1995, for example, less than $1 \%$ of all babies born to never-married women in the US were relinquished for adoption. See Chandra, et al. (1999).

${ }^{9}$ Some high school dropouts do end up obtaining a GED, but as Cameron and Heckman (1993) also find, such certificates are not equivalent to receipt of high school diplomas in terms of lifetime earnings or employment.
} 
The remainder of the paper is organized as follows. Section 1 reviews the multi-disciplinary literature on risky behaviour and positions our reputation model in the economic literature of intra-familial interactions. Section 2 characterizes the repeated two-stage game played by parents and their adolescent children, and spells out each player's equilibrium strategy. Section 3 outlines the empirical implications of this model, specifies the econometric models we estimate and discuss two alternative explanations for birth order differences in adolescent risk-taking behaviours and in responses to these behaviours in terms of parental financial transfers to their adult children. Section 4 describes the data. Section 5 presents the empirical estimates and assesses the validity of the reputation model relative to alternative explanations for finding birth order effects in adolescent risk-taking and parental financial responses to such behaviours. The last section offers concluding remarks.

\section{Literature Review}

A variety of factors have been found to be associated with adolescent risk-taking behaviour in the social science and psychology literatures, 10 including a youth's psychological makeup (low self-esteem), peer influences, the influence of the mass media, growing up in poverty and in poor neighbourhoods, social policies related to such behaviours, 11 hormonal changes during puberty (Booth, Carver and Granger 2000; Lehrer, Tremblay, Vitaro and Schaal 2004), and the interactions between these factors (Smetana, Campione-Barr and Metzger 2006). Other research has focused on the nature of adolescent decision-making, including how adolescents assess and/or discount the consequences of risky actions or how they (mis)perceive the likelihood of future consequences of such actions (Fischhoff 1992; O'Donoghue and Rabin 2001).

Regarding the interactions between parents and their children over adolescent risk-taking behaviour and how parents influence it, there is a well developed literature in psychology and sociology on the role of parents in influencing the behaviour of their adolescent children (Baumrind 1978; McLanahan 1985; Steinberg 2001) that focuses on the effects of alternative parenting strategies, parental control and parental monitoring on the incidence of such behaviours.

Within economics, there is a literature on the role of parents in parent-children interactions and family decision-making, 12 although its primary focus is not on adolescent risk-taking behaviour. Economic models of family interactions differ with respect to the structure of family decision-making (Alderman, et al. 1995; Bergstrom 1997). "Unitary" models view the family as a single unit, making resource allocation decisions so as to maximize a family's total welfare. Alternatively, "collective" models of the family focus on the individuality of family members and how these members reach (or fail to reach) collective decisions. 13

An important intermediate case between unitary and collective models of the family is encapsulated in Gary Becker's Rotten Kid Theorem (Becker 1974, 1991). Becker considered a two-stage game between altruistic parents and a selfish child. In the first stage, the child

\footnotetext{
${ }^{10}$ See Dryfoos (1990), Jessor (1991), Compas, Hinden and Gerhardt (1995), Steinberg and Morris (2001), and Smetanta, CampioneBarr and Metzger (2006) for surveys of the adolescent development literature, including adolescent risk-taking behaviours and their causes.

${ }^{11}$ See Gruber (2001); Chaloupka and Grossman (1996) and Evans and Huang (1997) on the effects of taxes and other policies on youth smoking; Dee and Evans (2001) on the effects of speed limits and safety belt laws on teen traffic safety; Levine (2001) on the effects of costs of becoming pregnant on the sexual activity and contraceptive practices of teens; Cook and Moore (2001) on the effects of excise taxes on teenage drinking; and Card and Lemieux (2001) on the effects of tuition costs and labour market conditions on the dropout and enrolment trends for youth in the US.

${ }_{12}^{12}$ See Behrman (1997) and Bergstrom (1997) for surveys of these models.

${ }^{13}$ See Chiappori $(1988,1992)$ for collective models in which the family is assumed to reach parent-efficient outcomes.
} 
decides whether to take some action (e.g., consumption). In the second stage, the parents decide whether to "reward" or "punish" this action by transferring or withholding resources to the child. Becker argued that altruistic parents can use financial transfers to induce the child to take actions that maximize the total well being of the family, even when parents do not directly control their child's behaviour. Becker claimed that the equilibrium outcome of this game is Pareto optimal, i.e., the outcome most preferred by the altruistic parents. Moreover, parents achieve this outcome even though they cannot pre-commit to a set of punishments or rewards that they would not be willing to undertake ex post.

Several subsequent studies have noted instances in which the game in Becker's Rotten Kid Theorem leads to allocative inefficiencies.14 Most notably, Bergstrom (1989) proves that the Rotten Kid Theorem is valid if and only if the preferences of the family are characterized by transferable utility. Under transferable utility, there exists a good (e.g., money) over which there is sufficient agreement among parents and children so that it can be used by the former to influence the latter's actions in order to maximize the family's total welfare. 15 Bergstrom (1989) establishes that families whose preferences are not characterized by transferable utility need not achieve an equilibrium to the parent-children game that is Pareto optimal, even when altruistic parents treat the utility of their offspring as a normal good. In the next section, we consider situations in which transferable utility need not hold for family preferences and examine a strategy parents may employ to induce some or all of its children to act in accordance with the altruistic parents' preferences.

Even when families have transferable utility, the implications of Becker's model of parentchild interactions may be sensitive to the presence of constraints on parent's income. Weinberg (2001) develops a model in which altruistic parents provide for their children's, as well as their own, consumption and try to influence certain actions that lead to long-term beneficial outcomes for the child and which their selfish child may undervalue. Becker $(1979,1991)$ refers to such actions as "merit" goods.16 Weinberg notes that such actions would include a child making an effort in school and/or abstaining from sex. Weinberg further assumes that altruistic parents maintain some minimal level of consumption, i.e., a consumption floor, for each of their children. Weinberg proves that poor parents, i.e., those for whom the floor on their children's consumption is binding, have less scope for influencing the actions of their children. As a result, Weinberg predicts that poor parents are more likely to resort to non-pecuniary mechanisms, such as corporal punishment, to influence their children than wealthier parents. Below, we explore how variation in the extent of the parents' financial constraints suggested by Weinberg might provide an alternative explanation to the reputation model we develop for birth order differences in adolescent risk-taking behaviour.

In this paper we extend the Becker model in two important dimensions. First, rather than focusing on the one-parent-one-child interaction, we consider a dynamic intra-familial model in which parents and each of their children engage in a repetition of Becker's game.

${ }_{15}^{14}$ See Lindbeck and Weibull (1988), Bruce and Waldman (1990), and Bergstrom (1989).

15 More formally, Bergstrom shows that a family's preferences are characterized by transferable utility if and only if the (private) utility of each family member $i$ is of the form,

$$
U_{i}\left(m_{i}, b\right)=A(b) m_{i}+B_{i}(b)
$$

where $b$ denotes a public good that all family members share, $m_{i}$ denotes the amount of money income allotted to member $i$, and $\Sigma_{i} m_{i}$ $=I$, where $I$ is the family's total income. The key feature of these preferences for the family's preferences to satisfy transferable utility is that the marginal utility of income is the same for all family members.

16 A merit good is one over which parents and children have conflicting preferences. 
Each child plays the two-stage game once, by birth order, whereas parents play through all rounds. Second, we relax the assumption that children have perfect information about their parents' preferences, especially with respect to their risk-taking behaviour. Given the irreversible results of some risk-taking actions and the inherent problem of parents providing credible commitments with respect to their treatment of such behaviours-especially in families that do not meet the conditions for Becker's Rotten Kid Theorem-we show that parents have an incentive to penalize older children for their risky behaviours in order to dissuade the younger ones from engaging in the same behaviours. Moreover, younger children can learn from the experience of older siblings in making their decisions about risktaking when they reach adolescence.

Our model draws on the reputation model of Milgrom and Roberts (1982) and Kreps and Wilson (1982) in repeated games. The model implies that the risk-taking behaviour of adolescent children and parental responses to this behaviour will vary systematically with birth order. Furthermore, as we argue below, the reputation model and its predictions are distinguishable from alternative models that can generate birth order effects in such behaviours. While previous studies have documented the importance of birth order differences in various forms of parental investments in and attainment of a family's offspring, 17 our paper provides a new and theoretically-based motivation for such effects that generates testable implications.

\section{The Reputation Model}

To begin, we characterize the structure of the Becker model of interactions between a parent and one of her children over whether the latter engages in risky behaviours when he is an adolescent. $18 \mathrm{We}$ illustrate how the solution of this parent-child game will vary depending on whether the family preferences are characterized by transferable utility. We then develop the repeated game, reputational model for the interactions of the parent and all of her children as each of them reach adolescence.

Consider a selfish teenage child that maximizes his utility function,

$$
U_{c}\left(c_{c}, b\right)
$$

over his own consumption, $c_{c}$, and his own risk-taking behaviour, $b$, where $b=1$ if the child engages in a risky behaviour and $b=0$ if not. Assume that the parent has "private" preferences,

$$
U_{p}\left(c_{p}, b\right)
$$

over her own consumption, $c_{p}$, and the child's risk-taking behaviour, $b$, but that the parent also is altruistic and, thus, acts like a social planner who cares about the welfare of all family members, i.e., the family welfare function is given by

$$
W_{p}\left(U_{p}\left(c_{p}, b\right), U_{c}\left(c_{c}, b\right)\right)
$$

\footnotetext{
${ }^{17}$ For example, Black, Devereux and Salvanes (2005) find that birth order has a causal effect on a child's social and economic outcomes, where they use twin birth as an instrument for family size. They find that later-born women have lower earnings and are more likely to have a first birth as a teenager than women who were the first-born in their families.

${ }^{18}$ To simplify the discussion, we assume there is one parent (a female) and assume all of her children are males. In the empirical analysis presented below, we analyze two- and one-parent families that may have male and female children.
} 
Assume that the parent has an exogenously given income, $I_{p}$, to support her own consumption and that of her child, where she can choose to provide the child with financial transfers, $t$, where $t=1$ if the parent gives financial transfer to the child and $t=0$ if the parent withholds the transfer. For simplicity, we assume that the adolescent has no income and totally depends on parental transfers to support his consumption. Thus, the utility functions of the child and the "planner-parent" can be rewritten as

$$
U_{c}(t, b)
$$

$$
W_{p}\left(U_{p}\left(I_{p}-t, b\right), U_{c}(t, b)\right)
$$

respectively. From the planner-parent's standpoint, we assume that both the consumerparent's utility and the child's utility are normal goods and that $W_{p}$ has nice concavity properties to guarantee a unique solution to this game. For now, we also assume that both the parent and her offspring know each other's preferences as well as their own. We shall relax this assumption below. The parent and her adolescent child play the following twostage game. In Stage 1, the child chooses action $b$ to maximize his selfish preferences subject to the transfer he expects from his parent, conditional on $b$, i.e., $t=t(b)$. In Stage 2, the planner-parent decides on the transfer to her child, $t$, so as to maximize the family welfare, $W_{p}$.

To illustrate the potential differences in the outcomes of the parent-adolescent game, consider Figure 1. In the configuration of payoffs to the adolescent and the planner-parent in Figure 1, family welfare $\left(W_{p}\right)$ is diminished when the adolescent engages in a risky action ( $b$ $=1)$ while the adolescent prefers taking this action $(b=1)$ to not taking it $(b=0)$, conditional on a particular transfer response by the parent. At the same time, the values of payoffs for the selfish adolescent used in the figure reflect the fact that he prefers a positive transfer $(t=1)$ to not receiving one $(t=0)$, conditional on a particular risk-taking action. We shall maintain these properties of the parent's and child's preferences with respect to adolescent risk-taking behaviour throughout this paper.19

We present two cases in Figure 1, which differ with respect to the structure of family preferences. In particular, we consider the parent-adolescent two-stage game for families whose preferences satisfy transferable utility, which we refer to as transferable type families, and for those that do not satisfy transferable utility, which we refer to as nontransferable type families. Consider Case A in Figure 1, in which family preferences are transferable. The decision-tree and the resulting payoffs illustrate the game's equilibrium and its efficiency properties. While the planner-parent would always prefer her teenager not to engage in a risky action, her payoff is $W_{p}=-1$ if she withholds a financial transfer from her teenage child who engages in a risky behaviour, whereas it is $W_{p}=-2$ if she rewards his risk-taking action. In other words, a parent with transferable utility demands a high compensation for the bad action and therefore has a motivation to withhold transfers to an ill-behaving child. Knowing these payoffs and preferences, her child will choose not to engage in risky behaviour. As a result, the equilibrium is the "No Risky Action, Parent Rewards" outcome and it is the Pareto optimal solution to the game. In essence, the planner-

\footnotetext{
${ }^{19} \mathrm{We}$ note that it is possible that the parent actually prefers for their children to engage and/or that her child does not like engaging in risky behaviour. While possible, we focus on models with the properties outlined above to highlight the potential for conflict between the parent and her children and to determine how, if at all, the family is able to work out this conflict.
} 
parent is able to use transfers to induce her selfish teen to forego engaging in risky behaviour.

In Case B of Figure 1, we illustrate the divergence between the equilibrium for the parentadolescent game and Pareto optimality when the family has non-transferable preferences. In this Case, the planner-parent prefers to reward her adolescent with a transfer when he engages in a risky behaviour $\left(W_{p}=0.5\right)$ than to punish him by withholding it $\left(W_{p}=-1\right)$. This occurs because a parent with non-transferable utility does not demand compensation high enough to withhold transfers from the child. Knowing these preferences of his parent and given his own preferences for misbehaving, the adolescent in a family with nontransferable preferences will choose $b=1$ in Stage 1 and his parent will reward this behaviour with a transfer, even though she would clearly prefer $b=0$, ex ante. As a result, the game reaches a sub-optimal, "Risky action, Parent Rewards" equilibrium.

We now consider the parent playing the above game over her life cycle with each of her $N$ children when they reach adolescence. We label a child as the $k^{\text {th }}$ child if he has $k-1$ younger siblings. The first born is Child $N$, and the last-born is Child 1. In essence, this is a repeated game with $N$ rounds, each involving the parent and one child at adolescence by birth order. Each round conforms to the game described above, with one important exception. At the beginning of the dynamic game, we assume that the children do not know the family's preference type. 20 In particular, while the children know their own preferences, $U_{c}(\cdot, \cdot)$, they do not know their family's welfare function, $W_{p}(\cdot, \cdot)$, or their parents' private preferences, $U_{p}(\cdot, \cdot)$. While uncertain about the parent's preferences, the first-born (Child $N$ ) starts with a prior belief that the probability his family's preferences are non-transferable is $\pi_{N}$. We do not specify exactly how children form these prior beliefs, although it is reasonable to presume that they are influenced by their past interactions with the parent and from observing the parent-adolescent interactions in other families in the neighbourhood. As the game goes on, Child $k$ observes all the actions of older siblings and may update this belief to $\pi_{k}$ upon entering adolescence.

Given this uncertainty, Child $k$ chooses an action, $b$, based on $\pi_{k}$ and the expected parental response to the action. Playing throughout the whole game, the parent chooses a sequence of financial transfers so as to maximize the discounted sum of utility derived from the choices of all of her children and her own consumption choices, i.e.,

$$
\sum_{k=N}^{1} \delta^{N-k} W_{p}\left(t_{k}, b_{k}\right),
$$

where $\delta$ is the publicly known discount factor. The parent's choice of financial transfer in round $k$ of the game is conditional on Child $k$ 's behaviour and the updated belief, $\pi_{k}$. Note that (6) is assumed to be additively separable across the $N$ children, i.e., the parent values each of her children and their actions in the same way, but for discounting. A perfect Bayesian equilibrium exists if at any point of the game: (i) a player's strategy prescribes optimal actions from that point on given the opponents' strategy and the relevant belief, and (ii) the belief is consistent with the strategies being played.21

\footnotetext{
${ }^{20}$ Examining the consequences of other forms of uncertainty in parent-children interactions is also of potential interest. For example, it is possible that parents are uncertain about their children's true preferences over risky actions. Another interesting source of uncertainty is the possibility that parents are unable to observe directly whether their children engage in risky behaviours, e.g., whether they smoke, drink alcohol, or use drugs. Allowing for the latter type of uncertainty is a focus of our future work on parental responses to adolescent risk taking.

21 Mas-Colell, Whinston and Green (1995), 283-285.
} 
Following Kreps and Wilson (1982), we define a sequence of belief thresholds, $\left\{\bar{\pi}_{k}\right\}$, where

$$
\bar{\pi}_{1}=\frac{U_{c}(t=1, b=0)-U_{c}(t=0, b=1)}{U_{c}(t=1, b=1)-U_{c}(t=0, b=1)}
$$

and

$$
\bar{\pi}_{k}=1-\left(1-\bar{\pi}_{1}\right)^{k}
$$

The numerator in (7) represents the maximum cost for a child engaging in the risky behaviour, while the denominator denotes the benefits of both taking the risky action and obtaining parental support. Therefore, $\bar{\pi}_{1}$ represents the "cost-benefit" ratio that makes a child indifferent to engaging in the risky behaviour in the static Becker model. If the youngest child believes the family's preferences are more likely than $\bar{\pi}_{1}$ to be nontransferable, the child will engage in the risky behaviour because the benefits of this action outweigh the costs. As one moves up the birth order from the youngest to the oldest, there is a greater reputation gain to the planner-parent of a family with non-transferable preferences for punishing the risky behaviour. For Child $k$ to choose the risky action, this child must believe that his family's preferences are non-transferable with a probability as high as $\bar{\pi}_{k}$. Apparently, $\bar{\pi}_{k}$ increases with $k$.

Assuming that the parent is sufficiently patient, the perfect Bayesian equilibrium for the $\mathrm{N}$ child family can be described in three regimes.

Regime 1 consists of all children older than Child $k^{*}$, where the prior belief of the first-born child, $\pi_{N}$, falls between $\bar{\pi}_{k^{*}}$ and $\bar{\pi}_{k^{*}+1}$ In Regime 1, the reputation gain is so great that the parent, with probability 1 , will punish all children who engage in risky behaviour. Given this punishment policy, all children in Regime 1 avoid risky behaviour. Since no risky behaviour occurs in Regime 1, the children's belief that their family has non-transferable preferences remains equal to $\pi_{N}$. Obviously, the more likely the children believe their family's preferences are transferable (i.e. the smaller the $\pi_{N}$ ), the more children, or rounds of the repeated game, fall into Regime 1, and, thus, the more children the parent can deter from engaging in risky behaviours.

In Regime 2, which starts with Child $k^{*}$, the gain to the planner-parent in families with nontransferable preferences from establishing a reputation for punishing bad behaviour reduces to a level that enables the parent to adopt a randomized strategy for determining the parent's transfer response to her child's risky behaviour choice. In particular, the parent chooses to punish the $k^{\text {th }}$ child $\left(k<k^{*}\right)$ by withholding a transfer with probability

$$
p_{k}=\frac{1-\pi_{k}}{\pi_{k}} \cdot \frac{\bar{\pi}_{k-1}}{1-\bar{\pi}_{k-1}}
$$

(For the parent with transferable preferences, the probability of punishing her children's risky behaviour remains equal to 1.) Let $n^{*}$ represent the first round in which the parent acquiesces and rewards her child's engagement in the risky behaviour with a transfer. (By definition, $n^{*}<k^{*}$.) For Child $n^{*}$, the family's preferences are revealed to be nontransferable. Define the interval $n^{*} \leq k \leq k^{*}$ as Regime 2 and $k<n^{*}$ as Regime 3. In Regime 2 , although the parent employs a randomized punishment strategy for whether to acquiesce and reward her child's risk-taking with a transfer, her transfers to any ill-behaving child in 
this Regime are $t=0$. Mimicking the parent's strategy, the $k^{\text {th }}$ child in Regime 2 follows a randomized strategy, engaging in the risky behaviour with probability smaller or equal to

$$
\rho=\frac{W_{p}(t=1, b=1)-W_{p}(t=0, b=1)}{W_{p}(t=1, b=0)-W_{p}(t=1, b=1)} .
$$

The numerator in (10) represents the one-period gain (to the social-planner parent) of providing an ill-behaving teen with financial transfers, while the denominator represents the utility gain from providing such transfers to a well-behaving child relative to providing such transfers to a child that engages in the risky behaviour.

Finally, in Regime 3, parental reward to an ill-behaving child reveals the family's preference to be non-transferable. Since the family's preference type is no longer uncertain, the equilibrium reduces to the static game equilibrium, i.e., "Risky Action, Parent Rewards," for all $k<n^{*}$.

The three-regime equilibrium only holds when the planner-parent is sufficiently patient.22 Kreps and Wilson (1982) show that as $\delta$ becomes sufficiently small, only Regime 3 exists in the equilibrium. In that case, the planner-parent in a family with non-transferable preferences lacks an incentive to establish a reputation for punishing the risky behaviour of any child, since the discounted benefits of obtaining greater conformity by younger children in the future is always exceeded by the costs of punishing older children. In the empirical analysis presented below, we propose a strategy for detecting the impact of parents' discounting of future payoffs on children's risk-taking choices and parental transfer responses to them.

Finally, we note that this three-regime equilibrium of the reputation game is appropriate for families with non-transferable preferences. For parents of families with transferable preferences, we presume that the equilibrium to the reputation game consists only of Regime 1 in which the parent punishes risky behaviour of all of her children. As a result, all of the children eventually learn that their family is a transferable preference type.

\section{Testable Implications and Econometric Specifications}

\subsection{Testing the Reputation Model}

In principle, one could estimate and test the implications of the reputation model of parentchild interactions by estimating a fully structural representation, i.e., specifying a family's prior belief, $\pi_{N}$, as a function of parent, family and neighbourhood characteristics, parameterizing the family's preference functions, solving for optimal choices at a stage of the game, updating the belief by the Bayes' rule based the actions and parental transfer responses for all of the older siblings, and then repeating this solution iteratively for all $\mathrm{N}$ children. Unfortunately, implementing this estimation strategy is compromised in the absence of data on a family's complete behaviour-transfer history for all rounds (children) of the game. For the data set used in this paper-the NLSY79-we only have data on the actions of children and the transfer histories for a subset of the children in a family, namely

\footnotetext{
${ }^{22}$ Technically, the above equilibrium is a unique sequential equilibrium for the finitely repeated dynamic game. The equilibrium is also robust to two-sided uncertainty; that is, the child may have private information about a preference toward teenage risky behaviours. In that case, parental strategy is exactly the same as before, as long as every child's preference conforms to a publicly known distribution and every child's preference is independent from each other. (Otherwise, the parent may learn the child's preference throughout the game, which would substantially complicate the game structure.) Children's strategy would take into account their own preferences, which may explain why not every youngest child engages in risky behaviours and not every older child in a big family avoids risky behaviours.
} 
those NLSY79 respondents who were between the ages of 14 and 21 in 1979. As a result, we are unable to appropriately update the $\pi$ 's for the sample children, since that updating depends on the past behaviours and the parents' transfer responses to all of their older siblings, some of whom are not included in the NLSY79.

Given the limitations of our data, we test the implications of the reputation model using a less "structural" formulation of the risk-taking decisions of adolescent children, parents' respond to such behaviours with respect to their financial transfers, and the variation in each behaviour by the number of siblings under the age of 18 at the time when each decision is made.

The reputation model generates two sets of predictions about parental transfer responses to risky behaviour and the incidence of the risky behaviour itself. The first prediction concerns "birth order effects" in parental transfer responses, or, more precisely, how these responses vary with the number of younger siblings that remain at risk to engage in risky behaviours. The reputation model predicts that parents of families with non-transferable preferences, in the face of their children's uncertainty about their family preference-type, are more likely to punish older children for engaging in risky behaviours to deter such behaviour among their younger children, where the benefits of establishing a reputation for punishment increases with the number of younger siblings. Second, if planner-parents discount the future when evaluating family welfare, i.e., $\delta<1$, then the welfare benefits from establishing a reputation for punishing risky-behaviours should be less the greater the gap in ages between the child in question and the next younger sibling at risk.

Based on these predictions, we consider the following econometric specification of the parental transfer response functions:

$T_{i j t}^{*}=\alpha_{i j}+\alpha_{1} B_{i j}+\alpha_{2} N Y G_{i j t}+\alpha_{3} A G A P_{i j t}+\alpha_{4} B_{i j} N Y G_{i j t}+\alpha_{5} B_{i j} A G A P_{i j t}+f_{T}\left(z_{i j t}^{c}, z_{i j t}^{p}\right)+e_{i j t}$,

$$
T_{i j t}=\left\{\begin{array}{l}
1, \text { if } T_{i j t}^{*} \geq 0 \\
0, \text { otherwise }
\end{array}\right.
$$

where $T_{i j t}^{*}$ is index function for $T_{i j t}$ choice; $T_{i j t}=1$ if parent $j$ provides financial transfers to child $i$ when he is age $t, t>18$, and $=0$ otherwise; $B_{i j}=1$ if child $i$ in family $j$ has engaged in a risky action during teen age and $=0$ otherwise; $N Y G_{i j t}$ is number of younger siblings are under age 18, when child $i$ is age $t ; A G A P_{i j t}$ is the age gap between child $i$ and the next younger sibling who is under age 18 at $t$; and $f_{T}\left(z_{i j t}^{c}, z_{i j t}^{p}\right)$ is a flexible function of child characteristics $z_{i j t}^{c}$ and parent characteristics, $z_{i j t}^{p}$.

The reputation model implies that $\alpha_{4}<0$ and $\alpha_{5}>0$ for families that have non-transferable preferences. For such families, the three-regime equilibrium implies a step function of parental transfer by birth order: conditional on children undertaking risky behaviours, parental transfers are withheld for earlier-born children (in Regimes 1 and 2) but granted to later-born children (in Regime 3). A linear approximation of this step function implies that $\alpha_{4}<0$. Mathematically, a smaller discount factor $(\delta)$ shifts the turning point of the step function towards a higher birth order. This shortens Regimes 1 and 2 and expands Regime 3, implying an increase in the transfer level averaged across all three regimes. To the extent that $\delta$ decreases with the age gap between the ill-behaving child and the next oldest sibling 
under age 18, we would expect the age gap has a positive impact on the likelihood of a transfer to the ill-behaving child, i.e., $\alpha_{5}>0.23$

An important issue for the estimation of the parental transfer reaction function specified in (11) and (12) is the potential endogeneity of $B_{i j}$. The $i^{\text {th }}$ child's adolescent risky behaviour depends on the belief the child had about his/her family's preference type at adolescence, which in turn depends on the characteristics of child $i$ and family $j$ at that time. Due to the dynamic nature of the game, parental transfer depends on that belief as well, giving rise to the endogeneity of $B_{i j}$ and its interactions with $N Y G_{i j t}$ and $A G A P_{i j t}$ in the parental transfer response function in (11).

To minimize this source of bias, we include a child-specific fixed effect, $\alpha_{i j}$, in the specification of the parental transfer response function in (11). To see why including $\alpha_{i j}$ in (11) minimizes this bias, recall that we examine parental transfers after the child reaches adulthood (age 18). At that point, the child's adolescent behaviour is predetermined and cannot change over time. Furthermore, the belief about his family's preference type that the child had when he made his choice of $B_{i j}$, as well as personal or family preferences that influenced this choice, also are determined prior to his/her reaching adulthood. As a result, including $\alpha_{i j}$ absorbs the influence of all of these factors and their potential contamination of the effects of $B_{i j}$ on the subsequent $T_{i j t}$ 's.24 Finally, note that by including fixed effects for child $i$ in family $j$, the coefficients $\alpha_{4}$ and $\alpha_{5}$ are identified by the changes in NYG (AGAP) that arise when that child's next younger sibling reaches adulthood (age 18) and are no longer at risk for adolescent risk-taking behaviour. While using this "aging out" of younger siblings to identify $\alpha_{4}$ and $\alpha_{5}$ is consistent with the reputation model, this variation may be consistent with other theories as well. We consider this possibility in Section 3.2 below.

The reputation model also predicts birth order and discounting effects on adolescent risktaking behaviour. First, the parent's incentive to build a reputation for penalizing the risktaking behaviour of their children implies that the older children, foreseeing such reputation incentives, are less likely to engage in such behaviours than the parents' younger children. Second, the closer the $i^{\text {th }}$ child is in age to his/her next oldest sibling, the greater are the benefits of establishing a reputation for punishing risky behaviours, and, therefore, the stronger is the incentive for that child to avoid risky behaviours. This implies that the specification of the $i^{\text {th }}$ child's risk-taking behaviour is:

$$
\begin{gathered}
B_{i j}^{*}=\beta_{j}+\beta_{1} N Y G_{i j t}+\beta_{2} A G A P_{i j t}+f_{B}\left(z_{i j}^{c}, z_{i j}^{p}\right)+e_{i j t}, \\
B_{i j}=\left\{\begin{array}{l}
1, \text { if } B_{i j}^{*} \geq 0 \\
0, \text { otherwise },
\end{array}\right.
\end{gathered}
$$

\footnotetext{
${ }^{23}$ Recall that for families that have Transferable preferences Bergstrom (1989) establishes that Becker's Rotten Kid Theorem holds. Given the "equal-caring" specification of family welfare (up to discounting) in (6), it follows that parents will not vary their transfers responses to risk-taking behaviours by the birth order of their offspring. Accordingly, for these families, $\alpha_{4}=\alpha_{5}=0$. Since we cannot independently determine the preference type of families, our sample consists of an unknown (to us) mixture of families by preference type. It follows that the actual estimates of the coefficients of the parental transfer response function in (11) and (12) will be a weighted average of the effects for these two preference types. Nonetheless, it follows that the reputation model still implies that $\alpha_{4}<$ 0 and $\alpha_{5}>0$, so long as there are at least some families with Non-Transferable preferences in the population (sample).

${ }^{24}$ Including $\alpha_{i j}$ in (11) implies that the direct effect of $B_{i j}$, $\alpha_{1}$, is not identified. However, because the coefficients on $B_{i j} \cdot N Y G_{i j t}$ and $B_{i j} \cdot A G A P_{i j t}$ are identified we still can test the predictions of the reputation model.
} 
where $B_{i j}^{*}$ is the index function of $B_{i j}$ and, again, $f_{B}\left(z_{i j}^{c}, z_{i j}^{p}\right)$ is a flexible function of $z_{i j t}^{c}$ and $z_{i j t}^{p}$. The reputation model predicts that $\beta_{1}<0$ and $\beta_{2}>0$. The logic of these predictions follows from what characterized parental transfer decisions, with the exception that these predictions hold regardless of whether the children are from families with transferable or non-transferable preferences. The latter is true since the children, ex ante, do not know their family's true preference type and only are able to learn it when their parents do not punish the risk-taking behaviour of an older sibling.

We control for family fixed effects, $\beta_{j}$, in the estimation of (13) and (14) in order to account for the influence of unobserved (to the econometrician) factors that are expected to influence the $i^{\text {th }}$ child's risk-taking behaviour-including $\pi_{N}$, as well as other family and neighbourhood characteristics that might be expected to affect the formation of $\pi_{N}$. We draw attention to two of the latter factors. First, controlling for $\beta_{j}$ accounts for the influence of the fertility preferences of parents of families that completed all of their childbearing prior to their $i^{\text {th }}$ decision about $B_{i j}$. Since this is true for most of the observations in our data, eliminating those few families whose number of children changed after this decision does not affect any of our conclusions. Second, $\beta_{j}$ also accounts for the influence of the risktaking behaviour and parental responses to all of the $j^{\text {th }}$ family's children older than the oldest child in that family included in our analysis sample. (The data we use for analysis, the NLSY79, includes a subset of families with more than one respondent.)

While the inclusion of family fixed-effects in the specification of (13) and (14) deals with the potential sources of bias described above, estimates produced for this specification may not be robust to certain generalizations of the reputation model. For example, parents may alter their preferences concerning their children's engaging in risky behaviours as they learn the consequences of such risky behaviours from experiences with their older children. Similarly, as a result of imperfect financial markets, parents' and adult children's disposable incomes may follow a life-cycle pattern rather than remain constant as the reputation model assumes. (We discuss both generalizations in Section 3.2.) Under either generalization, our estimates of reputation effects might be biased. To minimize these potential sources of bias, we control for an extensive set of observable time-varying parental and child-specific characteristics. These include the age of parents at time $t$, to proxy for the influence of timevarying factors determining parental income and/or the evolution of parental tastes, as well as the $i^{\text {th }}$ child's age and other time-varying child-specific characteristics. We provide a complete list of these variables in Section 5.

\subsection{Alternative Explanations for Birth order Effects}

The reputation model implies birth order effects in how parents respond to the risk-taking behaviours of their adolescent children as well as the incidence of risk-taking by their children. More precisely, this model generates predictions about the sign and significance of the interaction of an adolescent's risk-taking $\left(B_{i t}\right)$ and the number of younger siblings who are younger than age $18\left(N Y G_{i j t}\right)$ on their parents' provision of financial transfers $\left(T_{i j t}\right)$ and of $N Y G_{i j t}$ on whether the child engaged in risky behaviour as an adolescent $\left(B_{i t}\right)$. However, there are other explanations for finding non-zero birth order effects that have nothing to do with parental reputation. In this section, we briefly describe two such alternative explanations and how we might distinguish them from our reputation model.

3.2.1 Parental Resource Dilution-We first consider an extension of what the sociological literature has labelled as the "Resource Dilution" explanation for birth order effects in parental investments in their children. Suppose that parental resources available to invest in their children are more "diluted" early, relative to later, in the parents' life cycle, given that parental income tends to rise over time and/or that parental "fiduciary" 
responsibilities for their children decline as their older children reach adulthood. Powell and Steelman (1995) and Steelman, et al. (2002) argue that such resource dilution can explain their finding that first-born children are less likely to receive financial assistance for college and other forms of financial transfers than are later-born children. A variant of this hypothesis also may provide an alternative explanation to the reputation model developed above. We characterize this hypothesis and examine how its empirical implications differ from those of the reputation model.

Consider parents who, as before, allocate their income, $I_{p \tau}$, when they are age $\tau$ to the consumption of family members, either directly or indirectly through financial transfers. Parents are assumed to have greater fiduciary responsibilities for their children before they reach adulthood. Following Weinberg (2001), assume that altruistic parents always provide some minimum level of consumption, $\underline{c}$, to meet the "nutrition" and "other living essentials" needs for each of their non-adult children. (Parents are not "obligated" to provide for any of the consumption of their adult children.) For simplicity, we assume that $\underline{c}$ does not vary with the ages of non-adult children and that parents always provide at least $\underline{c}$ for themselves.25

Let the total number of family members for which parents have this responsibility at $\tau$ be $M_{\tau}=2+N_{\tau}^{<19}$, where $N_{\tau}^{<19}$ is the number of children under the age of 18 at $\tau$ and where we assume that there are two parents in the family.26 It follows that the family's minimal consumption needs at $\tau$ are Need $_{\tau}=M_{\tau}$, so that the family's Income-to-Need Ratio is give by $R_{\tau}^{I-N} \equiv I_{p \tau} /$ Need $_{\tau}$. A family is financially constrained, or In Poverty, at $\tau$ if $R_{\tau}^{I-N} \leq 1.27$ It follows that parents In Poverty at age $\tau\left(R_{\tau}^{I-N} \leq 1\right)$ do not have sufficient income to provide any financial transfers $\left(T_{i^{\prime} t}\right)$ to their adult children $(t>18)$. In contrast, parents that are not financially constrained $\left(R_{\tau}^{I-N}>1\right)$ have sufficient income to allocate some of their income to provide such transfers, if they so choose.

There are three cases concerning the financial situation of parents to consider:

Case 1: Families always financially constrained, i.e., are always In Poverty (InPov), if and only if $R_{\tau}^{I-N} \leq 1$, at each age $\tau$ of the parents' life cycle.

Case 2: Families never financially constrained, i.e., are always Out of Poverty (OutPov), if and only if $R_{\tau}^{I-N}>1$, at each parental aget.

Case 3: Families In and Out of Poverty (In\&OutPov) if and only if $R_{\tau}^{I-N} \leq 1$ at some ages $\tau$ and $R_{\tau^{\prime}}^{I-N}>1$ at all other ages $\tau^{\prime}$.

The most interesting circumstance for Case 3 is when families are financially constrained early in their life cycle, because $I_{p \tau}$ is low and/or because parents are financially responsible for all of their children, but experience an increase in their income relative to their consumption needs over time as either parental income increases or their older children become adults and leave the household.

We now consider the implications of this resource dilution model for parental transfer responses to their children's risk-taking behaviour and the risky actions that children take:28

\footnotetext{
25 We also assume that the family not subject to any economies of scale in meeting these needs. In the empirical analysis below, we allow for both factors in determining a family's minimum consumption needs.

${ }^{26}$ In terms of resource dilution, we focus on the period in which a family has given birth to all its children and the family size decreases as the children grow out of teen age. Empirically, very few families had newborns during the sample period. When that occurs, we include the newborns in the calculation of family size.

${ }^{27}$ We note that this definition of poverty corresponds to the definition of poverty thresholds used by the US government to construct its official poverty statistics.
} 
Case 1 (always In Poverty) and Case 2 (always Out of Poverty) families will exhibit no birth order differences in the risk-taking behaviour of their children nor in parental financial transfer responses to such behaviour.

While there will be no birth order effects in either of these cases, whether children engage in risk-taking behaviours and how parents respond to them with respect to financial transfers will differ across these two cases. For families always In Poverty (Case 1), parents have to withhold financial transfers to all of their children, since they are always financially constrained. How their adult children respond to this lack of financial help depends on children's preferences. If their preferences for risk-taking is sufficiently strong, they will all engage in such behaviour $(B=1)$, even though they get no financial help from their parents. Alternatively, if children's preferences for risky behaviours are not sufficiently strong, all children in the family will avoid such behaviours $(B=0)$.

In contrast, how parents in Case 2 families respond to the risk-taking behaviours of each of their children and whether their children will engage in such behaviours depends on the family's preference type. If the family has transferable preferences, parents will choose to punish each of their children's risk-taking actions by withholding transfers $(T)$. Each child, knowing that their family's preferences are transferable, will choose not to engage in a risky behaviour $(B=0)$ since their parents will reward this behaviour with a financial transfer. Alternatively, if the family has non-transferable preferences, parents will choose to provide transfers when their children engage in a risky action $(B=1)$ and, knowing this, each of their children will choose to engage in risky behaviours.

Case 3 families will exhibit birth order differences in the risk-taking behaviour of their children and in parental financial transfer responses to such behaviour as the family moves out of poverty over the parents' life cycle.

The resource dilution model does imply birth order effects in the behaviour of Case 3 families as they move from being In Poverty, when parents are constrained to provide no resources to their (older) adult children, to being Out of Poverty, when parents have sufficient income to be able to choose whether or not to provide such resources to their younger children. However, whether parents in Case 3 families choose to provide financial transfers to their younger children, and how their children respond, again depends on the family's and children's preferences. In particular, whether older children, who will not receive transfers when their parents are financially constrained, engage in or forego risky behaviours $(B)$ will depend on their private preferences $\left(U_{c}\right)$, as is the case for all children in Case 1 families. And, what parents and children in Case 3 families will do after parents are no longer financially constrained depends on the family's preferences-transferable or nontransferable-just as is the case for Case 2 families. It follows that Case 3 families with transferable preferences will exhibit no birth order effects in either the incidence of risktaking behaviour by their children or in the parental responses to such behaviours. In contrast, however, for Case 3 families that have non-transferable preferences, the resource dilution model generates the same pattern of birth order effects as implied by our reputation model.

While it is possible that the resource dilution theory will generate the same birth order patterns in the behaviours of parents and their children as the reputation model, one can distinguish between them so long as there is variation in the financial statuses of the families in our data. In particular, regardless of family preferences, the resource dilution model

\footnotetext{
${ }^{28}$ To isolate the implications of the resource dilution explanation, we assume that children have perfect knowledge of their family's preference type, so there is no incentive for the parents to try to establish a reputation for their responses to their adolescents' risktaking behaviours. Rather, we assume that the static equilibrium repeats itself for each child (round of the game).
} 
implies that there should be no birth order effects in these behaviours for families that are either always In Poverty or always Out of Poverty. In contrast, under the reputation model, all parents that have adequate financial resources, no matter they grow out of poverty or are always out of poverty, have an incentive to establish a reputation for punishing their children's risky behaviours and, thus, will differentially treat their children by birth order. Furthermore, under the reputation model, older children, not knowing their family's preference type, will be more likely to forego engaging in risky behaviour compared to their younger siblings. Thus, we can distinguish the reputation model from the resource dilution model by testing for birth order effects among families that are always Out of Poverty.

3.2.2 Parental Learning-Another potential explanation for finding birth order differences in parental treatment of children's risk-taking behaviour is the possibility that parents change their attitudes (preferences) towards such behaviour as they gain "parenting" experience over time. However, how such learning would affect parents' treatment of their subsequent children is unclear. Some parents may not fully realize the consequences of adolescent risk-taking until their first-born child, who engaged in such behaviour, has grown up. Learning from this experience, parents could become stricter with their younger children, and, in turn, their younger children may behave better than their oldest sibling did. Note that this outcome of the parental learning process generates a birth order pattern with respect to parental transfer responses and adolescent risk-taking actions that are the opposite of those implied by the reputation model.

In contrast, suppose that first-time parents do not know exactly how to discipline a teenage child. In the face of uncertainty, risk-averse parents choose to error on the side of caution by being overly-strict with their first-born child. Recognizing that their parents will respond in this way, the first-born child would be less likely to engage in risky behaviours than his younger siblings. Given that their first-born child "behaves," parents decide that they can relax their standards with their younger children. In short, if parental learning leads to parents being more lenient with their younger offspring, one will generate birth order patterns that also coincide with the reputation model, especially if the parents learn gradually.

While we cannot devise a general test that distinguishes between the parental learning and reputation models, we can devise a test against the reputation model for the special case in which all of parents' learning takes place from rearing the first born. In this case, we should expect to see that parental transfer responses to the first-born child are significantly different from those to the later born children and that there should be no birth order effects in these responses for the later-born children. In contrast, the reputation model implies that parental responses to risky behaviours is only a function of the number of younger siblings (sisters), no matter whether the child is first born or not. Similarly, if all of the parental learning occurs on the first-born child, we should find that the first-born child is less likely to engage in risky behaviours than later born children and that there is no birth order effect on the likelihood that latter-born children engage in risky behaviours. Again, the reputation model predicts that the risk-taking behaviour depends on the number of younger siblings (sisters), no matter whether the child is first born or later born.

3.2.3 Other Factors-Finally, there may be other forces that generate temporal changes in parental transfer responses and adolescent risk-taking behaviours that coincide with birth order. In particular, parents and their children may experience changes in their resources and attitudes over their respective life cycles, both of which affect risk-taking and transfer behaviours. For example, suppose that as children grow older they "mature" and this leads to improved parent-child communication and "tolerance" of each other's attitudes and behaviours. Such maturing by their children could lead parents to alter their parental transfer 
responses as both parent and child age, which confound the birth order effects associated with reputation formation. While we do not explicitly model such factors, we attempt to mitigate their impact on our estimates of the birth order effects associated with the reputation model by including polynomials in parental age and the age of the child whose risk-taking behaviour is being analyzed in the specifications of the parental transfer response function in (11) - (12) and the adolescent risk-taking behaviour equations in (13) - (14).

\section{Data}

This study uses data from the 1979 through 1996 waves of the National Longitudinal Survey of Youth 1979 (NLSY79).29 The NLSY79 consists of a nationally representative sample of US youth between the ages of 14 to 21 in 1979. Note that we can estimate the coefficients of the specification of the parental transfer response function in (11) and (12) with the full sample of NLSY79, since we have information on parental transfers to a given child at multiple ages beyond age 18 . However, in order to identify the family fixed effects included in specification of adolescent children's risk-taking choice equations in (13) and (14), we must restrict our analysis to the subset of the respondents in the NLSY79 who have at least one sibling in the sample. Because teenage childbearing behaviour only applies to female respondents, the study of teenage childbearing is limited to females only.

The NLSY79 sample design selected all respondents between the ages 14 and 21 (by January 1, 1979) who resided in surveyed households that were drawn in 1978. Of the 11,323 civilian respondents originally included in NLSY79 with non-missing transfer values, the multiple-sibling sample consists of 5,569 respondents for the analysis of high school dropouts. For the analysis of teenage childbearing, the full sample contains 4,926 females, 1,524 of whom have at least one sister interviewed in NLSY79.30

The NLSY79 gathered an extensive set of data on its respondents in the 1979 baseline interview, in annual interviews through 1994 and biennial interviews since 1994. Included in this data are detailed education histories for all respondents, fertility histories for female respondents, as well as information about two forms of parental transfers beyond the age 18 (to be described below). In addition, we make use of a rich set of personal and family background characteristics gathered in the NLSY79 annual surveys.

The indicator of being a high school dropout is not having a high school diploma before age 20. The teen birth indicator is equal to 1 if a female respondent had a live birth prior to age 18. Based on these definitions, we estimate the risky behaviour specification using one observation per individual and measure the time-varying variables at the age of the occurrence of the risky behaviour, or at age 18 if no risky behaviour occurred.

We measure two alternative forms of parental transfers. The first form is a financial transfer, which is measured as a dichotomous variable that indicates whether a respondent's parents provided at least $50 \%$ of the respondent's annual expenses after age 18 . The second form is "co-residence transfer," again measured as a dichotomous variable that indicates whether the respondent was living in the parents' home after age 18.31

The reputation model draws attention to two key variables. The first variable, $N Y G$, is the number of siblings (sisters) under age 18 who could potentially drop out of high school (or become pregnant as a teen). The second variable, $A G A P$, is the age gap in years between the respondent and the next younger sibling (sister) who is still at risk (younger than age 18) for

${ }^{29}$ For a complete description of this survey, see Center for Human Resource Research (2001).

${ }^{30}$ The NLSY79 also included a supplementary sample of civilians who were in the military at the time the sample was drawn. None of the respondents in this supplementary sample had information on siblings so they were not included in our samples. 
dropping out of high school (having a birth as a teen). The $A G A P$ variable is time-varying within a child, because the identity of the next younger sibling under age 18 may change over time.

We are not able to determine the values of $N Y G$ and $A G A P$ for some offspring (daughter) observations, because the full sibship information was obtained only in the 1993 wave, 14 years after the first wave, so that the birthdates for some siblings in a respondent's family may be missing. For example, we have missing data on $N Y G$ for $27.4 \%$ of the all offspring person-year data and $11.4 \%$ for the number of younger sisters version of $N Y G$ in the daughters person-year data used to estimate the parental transfer response functions in (11) and (12). In both the parental transfer and risky behaviour regressions, we code all missing values of $N Y G$ and $A G A P$ to zero and always include a dummy variable for missing values of each of these variables.

In Section 3.2, we outlined several alternative theories that generate birth order effects in the responses of parental transfers to their child's adolescent risk-taking behaviours and whether or not the child engaged in such behaviours. The Resource Dilution theory generated predictions concerning birth order effects in parental transfer responses and risk-taking behaviours as a function of a family's Income-to-Need ratios over the period after the child reached adulthood. To characterize family Income-to-Need, we use the official US

definition for poverty thresholds. We form $R_{\tau}^{I-N}$ defined in Section 3.2.1 by taking the ratio of the family's 1978 income to the amount of income a family in 1978 would have needed to purchase a minimal consumption basket, where the income needed to purchase this basket is adjusted for number of adults in the household and the number of children under the age of 19.32 Such ratios are derived for each year in which respondents were adults (over age 18).

Using the resulting time series on $R_{\tau}^{I-N}$ for each child, we classified a child's family has being in one of four statuses:

a. "Families Always In Poverty" (InPov), i.e., families for whom $R_{\tau}^{I-N} \leq 1$ for all years after a child reached age 20;

b. "Families In and Out of Poverty" (In\&OutPov), i.e., families who moved from in poverty $\left(R_{\tau}^{I-N} \leq 1\right)$ to out of poverty $\left(R_{\tau}^{I-N}>1\right)$ as the child aged;

c. "Inc-to-Need $>1 \&<$ Top 50\%" (AbovePov), i.e., families who were always out of poverty but whose Income-to-Need ratio less than the top 50\% of the sample income-to-need distribution $\left(1<R_{\tau}^{I-N}<\operatorname{Median}\left(R^{I-N}\right) ; 33\right.$

d. "Families in Top 50\% of Inc-to-Need Distribution" (IncNeedTop50), i.e., families that always had an Income-to-Need ratio above the sample median of $R^{I-N}$.

The resource dilution model implies that families always In Poverty (InPov) and always Out of Poverty (OutPov) should exhibit no birth order effects in either the incidence of risk-

\footnotetext{
${ }^{31}$ It would be of interest to examine the effects of parental use of non-financial strategies for establishing a reputation for penalizing adolescent risk-taking behaviours. For example, parents might choose to impose restrictions on their adolescent children, such as grounding, curfews, and other restrictions on a child's privileges, in response to their risk-taking behaviours. While the use of such non-financial penalties might be are difficult to enforce after age 18, parents can use them to discipline ill-behaving children before age 18. To the extent that such non-financial punishments are effective, parents would rely less on establishing a reputation effect by withholding financial transfers to their adult children. Unfortunately, NLSY79 does not contain information about the use of such nonfinancial penalties by parents on the respondents in these data. However, if such methods are used and are effective, it is likely that our estimates of the birth order effects in parental financial transfer responses to the risk-taking behaviour of their children will likely be underestimated.

${ }^{32}$ See http://www.census.gov/hhes/www/poverty/poverty.html for descriptions of how these poverty thresholds and needs standards are calculated, as well as for tabulations of the needs standards by family composition for 1978 .

${ }^{33}$ The median of the distribution of annual family Income-to-Need ratios $\left(R_{\tau}^{I-N}\right)$ in our data is 3.28 .
} 
taking behaviour among adolescents nor in the parental transfer responses to such behaviour. This model does suggest the possibility that families who moved In and Out of Poverty (In\&OutPov) could exhibit birth order effects in these behaviours, depending on preferences of the planner-parents and the private preferences of their offspring. As noted in Section 3.2, we focus our tests of this resource dilution model on whether there are birth order effects among families who are always out of poverty. In particular, we distinguish two groups of out of poverty families-one just above poverty (AbovePov) and one for families whose income-to-need ratio is considerably higher (IncNeedTop50) - in order to conduct a more refined assessment of the resource dilution model.

The parental learning model also can generate birth order effects. Below, we examine a special case of this model, namely whether or not the birth order effects differed for offspring who were the first-born in a family versus later-born offspring. Accordingly, we defined a dummy variable, firstborn, which is equal to 1 if an NLSY79 respondent was the first born in her (his) family and equal to 0 otherwise.

Finally, we include three additional sets of covariates in all of our regression specifications. The first set includes parental age, age squared, parental education, measures of family structure, and indicators of parental receipt of welfare. These variables attempt to control for family- and parent-related that might influence behaviours as well as changes in parental preferences or tastes. The second set includes child characteristics, including the age, age squared, race, measures of cognitive ability and psychological state of the child whose risktaking behaviour is being analyzed. Finally, we include a third set of variables which measure community conditions, such as whether the family resides in the central city, the proportion of blacks and of poor people residing in the family's county of residence population, and the unemployment rates in the family's county of residence. The latter variables are included to capture the economic and social environment within which children and parents make decisions. Note that we only include those covariates in these sets that are time-varying in the parental transfer response functions, given that the latter already include child-specific fixed effects.

\section{Results}

In section 5.1 we present unadjusted estimates of parental transfer responses and adolescent risk-taking behaviours by birth order, i.e., by a child's number of siblings (sisters) who are younger than age 18. In section 5.2, we present coefficient estimates from the regression models for parents' transfer decisions and children's behaviour decisions developed in section 3.1 and some extensions that allow us to conduct formal econometric tests of the reputation model and the alternative explanations of resource dilution and parental learning.

\subsection{Unadjusted Estimates of Parental Transfer Responses and Adolescent Risk-Taking Behaviour}

5.1.1 Parental Transfers-Table 1 presents estimates of the proportion of offspring that receive co-residence or financial transfers from parents when over age 18. The proportions are grouped by whether the offspring have engaged in a certain risky behaviour as teens and by the number of siblings remaining at risk when parents made their transfer decisions. Panel A presents results for the incidence of adolescent children who drop out of high school and Panel B presents results by whether or not daughters began their childbearing when they were teens.

The first three rows of Panel A show that parents tend to withhold financial transfers from high school dropouts, but are equally likely to provide co-residence transfers to children who drop out of or remain in high school. In particular, 19\% of high school dropouts receive 
financial transfers from parents at ages older than 19. The corresponding figure is $24 \%$ for offspring who did not drop out of high school. Thus, the average "punishment" for an adolescent child dropping out of high school is a 5\% decline in the likelihood of receiving financial help from his or her parents.

The reputation model predicts that these punishments should increase with the number of younger siblings at risk for this behaviour. Towards the bottom of Panel A (under "(1) Minus (2)"), we display how the incidence of parental punishments in the form of coresidence and financial transfers change with the number of siblings under the age of 18 . As expected, for all families, going from 0 to 1 sibling at risk increases the dropout penalty in the form of co-residence transfers from $0 \%$ to $6 \%$. Similarly, the penalty in the form of financial transfer increases from $5 \%$ to $8 \%$.

Panel B of Table 1 reports corresponding statistics for parental responses to the incidence of teenage childbearing among their daughters. The birth order patterns of parental transfers to daughters having births as teens are similar to, but are more pronounced than, those we found for adolescents dropping out of high school. Parents are less likely to make transfers (co-resident or financial) to a daughter who has a birth as a teen. Consistent with the reputation model, going from 0 to 1 sister under 18 increases the penalty in the form of coresidence transfers from $7 \%$ to $19 \%$ and from $15 \%$ to $20 \%$ for financial transfers. Again, we note that these patterns are consistent with the reputation model developed above.

In Appendix Table A1, we present tabulations similar to those in Table 1 for the four family income-to-need groups defined in Section 4. The tabulations in the various panels of Table A1 indicate that the penalties for either dropping out of high school or teenage childbearing tend to be greater in families that were always well out of poverty-i.e., were in the top 50\% of the Income-to-Need distributions-compared to the other Income-to-Need groups. We also find that even families that were always in poverty tend to exhibit increasing declines in the likelihood of receiving a parental transfer as the number of siblings (sisters) under age 18 increases. Such findings cast doubt on the parental resource dilution theory, as the latter theory predicts that families that are always in poverty or are always out of poverty should not exhibit any differences in parental transfers by birth order.

5.1.2 Offspring Risk-Taking Behaviours-Table 2 presents estimates of the proportions of offspring who dropped out of high school and of daughters that gave birth as a teen by the number of younger siblings (sisters) remaining at risk for such behaviours. The results in Panel A are for the full sample of offspring (daughters), while those in Panel B are for the subset of the offspring (daughters) who have at least one sibling (sister) in the NLSY79 sample. The birth order patterns for the two forms of risk-taking behaviour are very similar and these patterns do not vary much across the two samples.

Based on our reputation model, we expect the proportion of offspring dropping out of high school (having a teen birth) to decrease with the number of siblings (sisters) at risk. This pattern does not show up in the estimates based on the sample of all families (Panel A). For this sample, the incidence of risky behaviours is substantially higher for offspring (daughters) with $3+$ younger siblings (sisters) than those with a small number of younger siblings (sisters), although the difference across having 0,1 , or 2 siblings (sisters) at risk is much smaller. However, as we demonstrate below, the counterintuitive pattern in Table 2 reflects not only the birth order differences within families but also the variation across families of different sizes. The latter source of variation in risk-taking is likely to be spurious. For example, low-income families are not only more likely to have children who engage in risky behaviours, they are also likely to have more children (Geronimus and Korenman 1992). In the next section, we present regression estimates in which we control 
for family fixed effects in order to eliminate these sorts of cross-family differences and, thus, isolate the within-family birth order differences in adolescent risk-taking behaviour.

In Table A2 of the Appendix, we present the same tabulations provided in Table 2 for the four family income-to-need statuses defined in Section 4. For both dropping out of high school and teen births among daughters, one finds that the incidence of these behaviours decreases as the income-to-need ratio of families increases. In addition, the birth order patterns of both risky behaviours vary with family income-to-need categories. In particular, the incidence of dropping out of high school increases with birth order in a more dramatic fashion among families that are always in poverty compared to families who are always out of poverty. Furthermore, while the incidence of teen births among daughters tends to increase (or remain constant) with birth order for most of the income-to-need categories, it actually declines among families who are in the top income-to-need group. Recall that the resource dilution model predicts no birth order effects for either families that are always in poverty or those that are always out of poverty. The unadjusted estimates for both types of risky behaviours presented in Table A2 appear to be inconsistent with the resource dilution story. Below, we examine whether these initial findings concerning the validity of the resource dilution model hold after controlling for family fixed effects and other covariates.

\subsection{Regression Results}

We now turn to the results from our multivariate regression analyses. Table 3 presents estimates for the basic specifications of the parental transfer response functions in (11) and (12) that control for child-specific fixed-effects as well as a range of time-varying individual, family and community characteristics and Table 4 presents estimates that examine the robustness of these basic findings to alternative specifications and the alternative explanations for birth order effects discussed in Section 3.2. In Table 5, we present estimates for the basic specifications of the adolescent risk-taking choice models in (13) and (14). Table 6 provides results for some robustness checks with respect to the implications of the reputation model and those of the alternative models. For the sake of space, we present only those parameters relevant for the reputation model and the alternative explanations.

5.2.1 Parental Transfers-Panel A of Table 3 displays estimates for parental transfers responses to whether their offspring drop out of high school, using the sample of all offspring, and Panel B presents corresponding estimates of parental transfer responses to their daughters having births as a teen, using the sample of all daughters in the sample. Both panels report the results for co-residence and financial transfers.

In Column (1) of Table 3, we present estimates concerning the primary prediction of the reputation model, namely, how parental transfer responses to risk-taking behaviours vary with the number of siblings (sisters) under the age of 18. For both co-residence and financial transfers and in response to either dropping out of high school or daughters having their first birth as a teen, we find negative and statistically significant coefficients on the $B \cdot N Y G$ interaction, implying that the more younger siblings (sisters) there are the greater is the likelihood that parents penalize these behaviours by withholding transfers to their offspring (daughters). Recall that the regressions that produce these estimates control for individual fixed effects and a range of time-varying covariates. Consistent with the unadjusted estimates presented in Table 1, these results lend further support to the reputation model.

In Column (2) of Table 3, we extend the basic specification of the reputation model to include the interaction between a respondent's risky behaviour and the age-gap between the respondent and his (her) next oldest sibling at risk $(B \cdot A G A P)$ in order to assess the model's predictions concerning how parental transfer responses vary with parental discounting of the 
future. According to the reputation model, the larger this age gap the less the parents will gain from establishing a reputation for penalizing the risky behaviour of the respondent. Our findings concerning the importance of parental discounting are mixed. With respect to parental transfer responses to whether their offspring drops out of high school, the estimated coefficients on this interaction are small in absolute value and not statistically significant for either co-residence or financial transfers. In contrast, the corresponding estimates of the effect of parental co-residence transfers in response to daughters' having teen births are positive and statistically significant, i.e., parents are less likely to withhold this form of transfer in response to the respondent who had a teen birth, the greater is the gap in age between the respondent and her next oldest sister. Taken together, the results for the effects of the interaction of $A G A P$ with $N Y G$ in Table 3 provide a less-than-clear-cut picture about the importance of discounting of the future and its consequences for the strength of the incentive for parents to form reputations for punishing the risk-taking behaviour of their adolescents, although the effect for co-residence transfers to teen births is consistent with how greater discounting of the future should reduce the incentives for parents to establish such a reputation.

It is worth emphasizing that after including the additional age-gap variables in the regressions, the basic reputation effect, captured by the coefficient on $B \cdot N Y G$, remains negative and statistically significant for both types of transfers and both types of behaviours (see Column 2). This finding provides some additional evidence concerning the robustness of the main implication of the reputation model.

One may wonder whether parental punishment for a daughter's teenage birth has any reputation effect on sons. In results not included in Table 3, we use the number of younger siblings instead of younger sisters in the parental transfer regressions pertaining to teen birth. The coefficients on $B \cdot N Y G$, with $N Y G$ re-defined in this way, remains negative and significant, although they are smaller in magnitude. For example, the estimated coefficient on this re-defined interaction in the co-residence transfer regression is -0.0668 compared to the corresponding estimate of -0.0953 in Column (1) of Table 3 . These results suggest that a parental reputation of being strict in response to teen birth may have some spill over effect on sons, albeit weaker than those for daughters.

In Table 4, we present results from several alternative specifications of the parental transfer response functions. The results presented in Column (1) allow the effect of $B$ to vary by the number of younger siblings (sisters) under age 18 in order to assess the robustness of the findings in Table 3 based on a continuous measure of $N Y G$. Interacting $B$ with dummies for 1,2 and $3+$ younger siblings (sisters), we find that the coefficients of the interacting terms become more negative as the number of remaining siblings moves from 1 to 2 , and to $3+$ for both co-residence and financial transfers. Thus, the birth order effects found with the continuous measure of $N Y G$ clearly do not distort the findings concerning the validity of the main prediction of the reputation model.

In Column (2) for both panels of Table 4, we present results for a specification of the parental transfer functions that assesses whether the birth order effects we have been attributing to the reputation model can be explained by the resource dilution model outlined in Section 3.2. In this specification, we add to the basic specification of the reputation model three-way interactions of our measures of $B$ and $N Y G$ with dummy variables for each of the four income-to-need categories defined in Section 4. Recall that the resource dilution model predicts that families that are always out of poverty should exhibit no birth order effects in parental responses to the adolescent risk-taking behaviour of their offspring, i.e., the coefficients on B.NYG.AbovePov and B.NYG.IncNeedTop 50 should both be equal to zero. For both forms of parental transfers and both types of adolescent risk-taking behaviours, we 
find that the coefficients on these triple interactions are always statistically significantly different from zero, clearly rejecting the implication of the resource dilution model of no birth order effects in these responses.34 Furthermore, the fact that these estimates are all negative and larger for families that have higher Income-to-Need ratios provides compelling evidence that the reputation model better characterizes how parental transfers respond to the risk-taking behaviour of their offspring (daughters) than does the resource dilution model.

Finally, in Column (3) of both panels of Table 4, we present estimates that assess the validity of the parental learning explanation of finding birth order effects in parental transfer responses. Specifically, we add to the basic model a two-way interaction NYG.firstborn and a three-way interaction $B \cdot N Y G \cdot f i r s t b o r n$, where firstborn is a dummy variable indicating the respondent's first-born status. If parental learning is an important factor in the way parent respond to the risk-taking behaviour of their children and this learning occurs with their first-born child, we should expect to find the coefficients on these interactions to be significantly different from zero and presumably negative, indicating that parents respond more harshly to the behaviours of the first-born relative to later-born children. The reputation model implies no differences in the effects of $N Y G$ and $B \cdot N Y G$ for first-born versus later-born children in the parental transfer response function. 35

With one exception, the estimated coefficients on these interactions involving the firstborn indicator are statistically insignificant for both types of parental transfers in response to either type of adolescent risk-taking. The one exception is the positive and significant coefficient for B.NYG.firstborn in Panel B of Table 4. Note that the sign of this effect implies that, relative to later-born daughters, parents are more likely to provide housing to their first-born daughter who had a teen birth, the more sisters under age 18 the daughter has. However, the marginal effect of $B \cdot N Y G$ on the first-born daughter's co-residence transfer remains negative and significant $(-0.1060+0.0338=-0.0722)$. Regardless of birth order status, the main prediction by the reputation model, namely how parental transfers respond to $B$ as a function of $N Y G$, is negative and significant for both forms of parental transfers and for both types of adolescent risk-taking. While these findings do not completely rule out the importance of parental learning in accounting for parental transfer responses, they do cast doubt that this alternative model does a better job than the reputation model in explaining the birth order patterns in our data.

Overall, the findings in Table 4 provide additional evidence in favour of the reputation model and suggest that neither the resource dilution nor parental learning models are consistent with how parental transfers responses to the risk-taking behaviours of children vary with birth order.

5.2.2 Offspring Behaviour-We now examine the regression results concerning how the risk-taking behaviour of offspring varies with number of siblings or sisters under the age of 18 (birth order), using the sibling (sister) sample. Table 5 reports results for the basic reputation model in two panels with Panel A for dropping out of high school and Panel B for having a teen birth. Table 6 provides results for some robustness checks with respect to the implications of the reputation model and those of the alternative models. All parameters are estimated with family fixed effects for multiple siblings (sisters) within families.

\footnotetext{
${ }^{34} \mathrm{We}$ also tested that in all cases we reject the null hypothesis that the coefficients on B.NYG.AbovePov and B.NYG.IncNeedTop5O are both equal to zero.

35 Under this special case of the parental learning model, we would also be interested in seeing if the direct effect of parental transfer responses to risky behaviours is different for first-born relative to later-born children. We cannot perform a test for this effect, since the effects of the interaction of firstborn with $B$ are absorbed by the child-specific fixed effects.
} 
In Column (1) of Table 5, we present estimates for the primary implication of the reputation model, namely the probability of a child (daughter) engaging in a risky behaviour decreases with the number of siblings (sisters) under 18. With respect to dropping out of high school (Panel A), the coefficient of the number of siblings under 18 (NYG) in Column (1) is negative and significant, a finding consistent with the reputation model. For teenage childbearing (Panel B, Column 1), the coefficient for $N Y G$ is negative but is imprecisely estimated. The large standard error on this coefficient estimate may occur due to the small sample size $(1,511)$ used to estimate these effects. Nevertheless, the negative signs of the coefficient on $N Y G$ in both panels are consistent with the reputation model.

In Column (2) of Table 5, we present results that assess the reputation model's predictions concerning how adolescent risk-taking behaviours vary with parental discounting of the future. Under the reputation model with discounting of the future, children who are much older than their next younger sibling should be more likely to engage in risky behaviours. For both dropping out of high school and teenage childbearing, the coefficients on the AGAP variable are not significantly different from zero. The weak results on the AGAP variable in the risky behaviour regressions suggest that this variable may not fully capture parents' value of the future. However, we again note that main reputation effect, namely the effect of $N Y G$ on risk-taking behaviour, continues to be negative and statistically significant for high school dropout after we control for $A G A P$, providing further support for the reputation model.

In Table 6, we present results for the same three alternative specifications adapted to the case of the risk-taking outcomes examined for parental transfer responses in Table 4. In Column (1) of both panels of Table 6, we present estimates of a specification in which we use dummy variables indicating the presence of 1,2 , and $3+$ younger siblings (sisters) in place of the continuous measure of $N Y G$ used in Table 5. While only the effect on 3+ siblings younger than 18 is statistically significant, we are able to decisively reject the null hypothesis that the three coefficients on the $N Y G$ dummy variables are equal to zero in the high school dropout regression.

In Column (2) of Table 6, we include interactions of $N Y G$ with dummy variables for the four Income-to-Need categories in order to assess whether the resource dilution model can account for the birth order patterns in the incidence of adolescent risk-taking. As before, we focus on the effects of $N Y G$ for families that are always above poverty (AbovePov) and those that are considerably above poverty (IncNeedTop50). For dropping out of high school, we find that there are negative and statistically significant birth order effects for both high Income-to-Need categories.36 Such effects are clearly inconsistent with the resource dilution model. With respect to teenage childbearing, we find that the coefficients on NYG.AbovePov and NYG.IncNeedTop50 are both negative and only the effect for the highest Income-to-Need category is significant.37 Thus, while the evidence against the resource dilution hypothesis is weaker in the case of teenage childbearing, it clearly does not offer support in favour of the resource dilution hypothesis over the reputation model.

Finally, in Column (3) of Table 6, we present estimates that assess the validity of the parental learning model by including firstborn and NYG.firstborn. If the parental learning model is true, the coefficients on these two variables should be significantly different from zero. For both high school dropout and teenage childbearing, we cannot reject that the coefficients on firstborn and NYG.firstborn are zero, either individually or jointly. Again,

\footnotetext{
${ }^{36}$ We are also able to reject the null hypothesis that the coefficients on NYG.AbovePov and NYG.IncNeedTop 50 are both equal to zero at the $5 \%$ significance level.

${ }^{37} \mathrm{We}$ are able to reject the null hypothesis that these two coefficients are both equal to zero at the $10 \%$ significance level.
} 
while not decisive, these results do not provide strong evidence that a parental learning model does a better job of accounting for the birth order patterns in adolescent risk-taking behaviour than the reputation model.

\section{Conclusion}

In this paper we introduce a new approach to modelling the interactions of parents and their children with respect to adolescent risk-taking. We draw on the model of reputation formation in repeated games to establish that parents may have an incentive to establish a reputation for punishing the risk-taking behaviour of their older children in order to dissuade their younger children from engaging in such behaviours.

The reputation model generates two empirical implications: the likelihood of teenagers' engaging in risky behaviours and parental transfers to children who engaged in risky behaviours during teen years will decrease as the number of siblings under age 18 increases. At least in the context of dropping out of high school and teenage childbearing, we find support for both of these implications. We also consider two alternative theories that can generate birth order effects in the incidence of adolescent risk-taking behaviour and in parental transfer responses to such behaviour, namely a resource dilution model and a model of parental learning. We find that neither model is consistent with the data for the particular risk-taking behaviours examined in this paper. More to the point, our evidence clearly indicates that the reputation model is far more powerful in explaining the data we analyze than either of these two alternatives.

To be sure, there are other factors that influence the risk-taking behaviours of adolescents. Community, school and public policies each may have an important impact on teenagers' behaviours as well. However, the reputation model for parent-child interactions that we have considered in this paper and the evidence that we present in its favour have several potentially interesting implications for understanding and affecting the risk-taking behaviour of adolescents. First, our analysis has suggested that parents, albeit altruistic in their preferences and attitudes towards their offspring, may be limited in their ability to control the potentially detrimental risk-taking behaviour of their children, due to the lack of sufficient compatibility in the preferences of parents and their children (i.e., not having transferable utility) to facilitate resolution of conflicts between them.

Second, although the reputation model we have considered in this paper clearly suggests a potential strategy for gaining some influence over such behaviour, the model also suggests that demographic trends, including declining family size, 38 may account for an increased incidence of "spoiled children," i.e., children who are less susceptible to parental influence. 39

Finally, our study suggests ways that society may help to strengthen parents' influence over their adolescent children and their behaviours. For example, the reputation model suggests that the child's stronger prior belief that their family's preferences are transferable increases the incentives for parents to establishing a reputation for punishing bad behaviour and

\footnotetext{
${ }^{38}$ Family size has declined substantially in the US over the last 20 to 40 years. Today, the typical woman in the US is expected to have 2.03 children over her lifetime. In 1970, the corresponding figure was 2.5 children and in 1960 it was 3.6 children. Source: Period-specific total fertility rate estimates taken from selected issues of National Vital Statistics Reports, Centre for Health Statistics, US Centre of Disease Control and Prevention.

${ }^{39}$ An article in the August 6, 2001 issue of Time magazine entitled, "Who's in Charge Here?" reported that $80 \%$ of American adults think that today's children are more spoiled than kids of 10 or 15 years ago were. 1 The article goes on to lament that today's youth are the most indulged generation in recent history: "Go to the mall or a concert or a restaurant and you can find them in the wild, the kids who have never been told no, whose sense of power and entitlement leaves onlookers breathless, the sand-kicking, foot-stomping, arm-twisting wheedling, whining despots whose parents presumably deserve the monsters they, after all, have created."
} 
rewarding good behaviour. To the extent that institutions, such as schools and other community organizations, can reinforce such prior beliefs, society may benefit from the enhanced ability of parents to better control the actions of their adolescent children.

\section{Acknowledgments}

This research was funded by a grant from the National Institute for Child Health and Human Development (R01HD34293). We wish to thank Robert Pollak, David Levine and Hongbin Cai for their suggestions at the initial stages of this research and to Gary Becker, Meta Brown, Andrew Cherlin, Wilbert van der Klaauw, Tomas Phillipson, Jack Porter, Paul Schultz, Duncan Thomas, participants in workshops at UC-San Diego, UC-Santa Barbara, Washington University, New York University, the NBER Summer Institute, George Mason University, the University of Chicago and the University of Wisconsin for comments on an earlier draft of the paper. Obviously, only the authors are responsible for the content of this paper.

\section{References}

Alderman H, Chiappori P-A, Haddad L, Hoddinott J, Kanbur R. Unitary versus collective models of the household: is it time to shift the burden of proof? World Bank Research Observer. 1995 February; vol. 10(1):1-19.

Baumrind D. Parental disciplinary patterns and social competence in children. Youth and Society. 1978 March; vol. 9(3):239-276.

Becker GS. A theory of social interactions. Journal of Political Economy. 1974 November; vol. 82(6): 1095-1117.

Becker, GS. A Treatise on the Family, Enlarged Edition. Cambridge, MA: Harvard University Press; 1991.

Behrman, J. Intrahousehold distribution and the family. In: Rosenzweig, MR.; Stark, O., editors. Handbook of Population and Family Economics. Vol. Vol. 1. New York: North-Holland; 1997. p. 125-187.

Bergstrom TC. A fresh look at the Rotten Kid Theorem - and other household mysteries. Journal of Political Economy. 1989 October; vol. 97(5):1138-1159.

Bergstrom, TC. A survey of theories of the family. In: Rosenzweig, MR.; Stark, O., editors. Handbook of Population and Family Economics. Vol. Vol. 1. New York: North-Holland; 1997. p. 21-79.

Black SE, Devereux PJ, Salvanes KG. The more the merrier? the effect of family size and birth order on children's education. Quarterly Journal of Economics. 2005 May; vol. 120(2):669-700.

Booth A, Carver K, Granger DA. Biosocial Perspectives on the Family. Journal of Marriage and the Family. 2000 November; vol. 62(4):1018-1034.

Bruce N, Waldman M. The Rotten-Kid Theorem meets the Samaritan's Dilemma. Quarterly Journal of Economics. 1990 February; vol. 105(1):155-165.

Bureau of Labour Statistics. NLSY79's User's Guide: A Guide to the 1979-2000 National Longitudinal Survey of Youth Data. 2001.

Cameron SV, Heckman JJ. The nonequivalence of high-School equivalents. Journal of Labour Economics. 1993 January; vol. 11(1):1-47.

Card D, Lemieux T. Can falling supply explain the rising return to college for younger men? A cohortbased analysis. Quarterly Journal of Economics. 2001 May; 116(2):705-746.

Center for Human Resource Research. NLSY79 User's Guide. Washington, DC: U.S. Department of Labor; 2001. www.bls.gov/nls/79guide/nls79usg.htm.

Chaloupka F, Grossman M. Price, tobacco control policies and youth smoking. NBER Working Paper 5740. 1996

Chandra, A.; Abma, J.; Maza, P.; Bachrach, C. Advance Data from Vital and Health Statistics, No. 306. National Center for Health Statistics; 1999. Adoption, adoption seeking and relinquishment for adoption in the United States.

Chesson HW, Blandford JM, Gift TL, Tao G, Irwin KL. The estimated direct medical cost of sexually transmitted diseases among American youth, 2000. Perspectives on Sexual and Reproductive Health. 2004 January/February; 36(1):11-19. [PubMed: 14982672]

Chiappori P-A. Rational household labour supply. Econometrica. 1988 January; vol. 56(1):63-89. 
Chiappori P-A. Collective labor supply and welfare. Journal of Political Economy. 1992 June; vol. 100(3):437-467.

Child Trends. Facts at a Glance. Washington, DC: Child Trends; 2003 November. www.childtrends.org/Files//Child_Trends_2003_01_01_FG_Edition.pdf.

Compas B, Hinden B, Gerhardt C. Adolescent development: pathways and processes of risk and resilience. Annual Review of Psychology. 1995; vol. 46:265-293.

Cook, PJ.; Moore, MJ. Environment and persistence in youthful drinking patterns. In: Gruber, J., editor. Risky Behaviour among Youth: An Economic Analysis. Chicago: University of Chicago Press; 2001. p. 375-438.

Dee, TS.; Evans, WN. Teens and traffic safety. In: Gruber, J., editor. Risky Behaviour Among Youth: An Economic Analysis. Chicago: University of Chicago Press; 2001. p. 131-166.

Dryfoos, JG. Adolescents at Risk: Prevalence and Prevention. New York: Oxford University Press; 1990.

Eng, TR.; Butler, WT., editors. The Hidden Epidemic: Confronting Sexually Transmitted Diseases. Washington, DC: National Academy Press; 1997.

Evans, WN.; Huang, L. Cigarettes taxes and teen smoking: new evidence from panels of repeated cross-sections. mimeo: University of Maryland; 1997.

Fischhoff, B. Risk Taking: A Developmental Perspective. In: Yates, JF., editor. Risk-Taking Behavior. Chichester: John Wiley; 1992. p. 133-162.

Geronimus A, Korenman S. The Socioeconomic Consequences of Teen Childbearing Reconsidered. Quarterly Journal of Economics. 1992 November; vol. 107(4):1187-1214.

Gruber, J., editor. Risky Behaviour among Youth: An Economic Analysis. Chicago: University of Chicago Press; 2001.

Hotz VJ, McElroy SW, Sanders SG. Teenage childbearing and its life cycle consequences: exploiting a very natural experiment. Journal of Human Resources. 2005 (Summer);vol. 40(3):683-715.

Jessor R. Risk behaviour in adolescence: a psychosocial framework for understanding and action. Journal of Adolescent Health. 1991; vol. 21:597-605. [PubMed: 1799569]

Kreps D, Wilson R. Reputation and imperfect information. Journal of Economic Theory. 1982 August; vol. 27(2):253-279.

Lehrer, S.; Tremblay, R.; Vitaro, F.; Schaal, B. Raging hormones in puberty: do they influence adolescent risky behaviour? Unpublished manuscript. Queen's University; 2004.

Levine, P. The sexual activity and birth-control use of American teenagers. In: Gruber, J., editor. Risky Behaviour Among Youth: An Economic Analysis. Chicago: University of Chicago Press; 2001. p. 167-218.

Lindbeck A, Weibull JW. Altruism and time consistency: the economics of fait accompli. Journal of Political Economy. 1988 December; vol. 96(6):1165-1182.

Mas-Colell, A.; Whinston, MD.; Green, JR. Microeconomic Theory. New York: Oxford University Press; 1995.

McLanahan S. Family structure and the reproduction of poverty. American Journal of Sociology. 1985 January; vol. 90(4):873-901.

Milgrom P, Roberts J. Predation, reputation and entry deterrence. Journal of Economic Theory. 1982 August; vol. 27(2):280-312.

National Center for Educational Statistics. Dropout Rates in the United States: 2000. Washington, DC: US Department of Education; 2001.

O'Donoghue, T.; Rabin, M. Risky behaviour among youths: some issues from behavioural economics. In: Gruber, J., editor. Risky Behaviour Among Youth: An Economic Analysis. Chicago: University of Chicago Press; 2001. p. 29-68.

Powell B, Steelman LC. Feeling the pinch: child-spacing and constraints on parental economic investments in children. Social Forces. 1995; vol. 73:1465-1486.

Smetanta J, Campione-Barr N, Metzger A. Adolescent development and societal contexts. Annual Review in Psychology. 2006; vol. 57:255-284.

Steelman LC, Powell B, Werum R, Carter S. Reconsidering the effects of sibling configuration: recent advances and challenges. Annual Review of Sociology. 2002; vol. 28:243-269. 
Steinberg L. We know some things: parent-adolescent relationships in retrospect and prospect. Journal of Research on Adolescence. 2001; vol. 11(1):1-19.

Steinberg L, Morris AS. Adolescent development. Annual Review of Psychology. 2001; vol. 52:83110.

Upchurch DM, McCarthy J. The timing of a first birth and high school completion. American Sociological Review. 1990 April; vol. 55(2):224-234.

Weinberg B. An incentive model of the effect of parental income on children. Journal of Political Economy. 2001 April; vol. 109(2):266-280. 


\section{Case A: Family with Transferable Preferences}

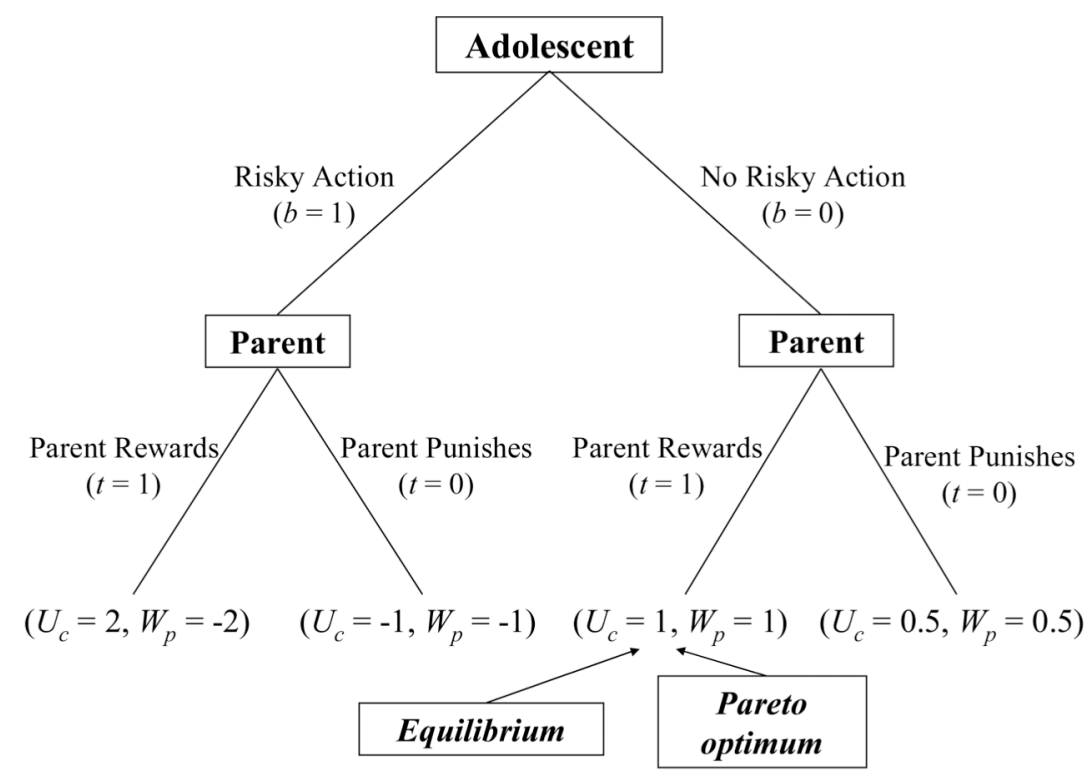

Case B: Family with Non-Transferable Preferences

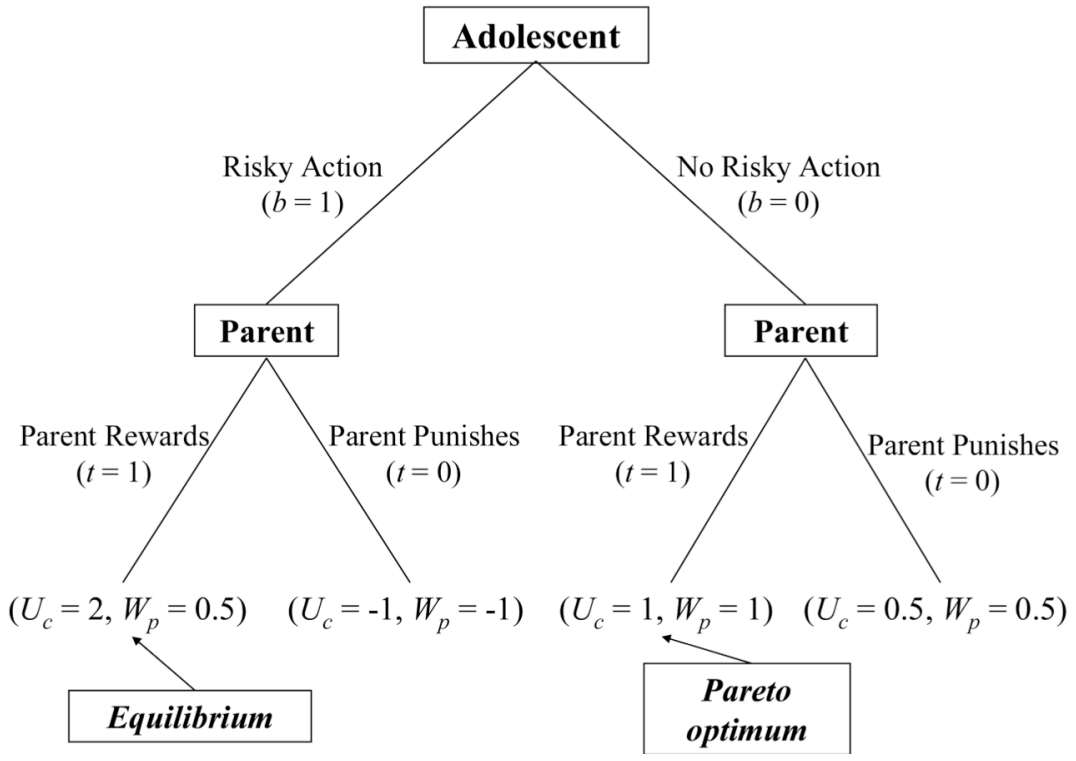

Fig. 1.

Decision Tree for Parents' and Teen's Decisions over (Teen's) Risk Taking Behaviour 


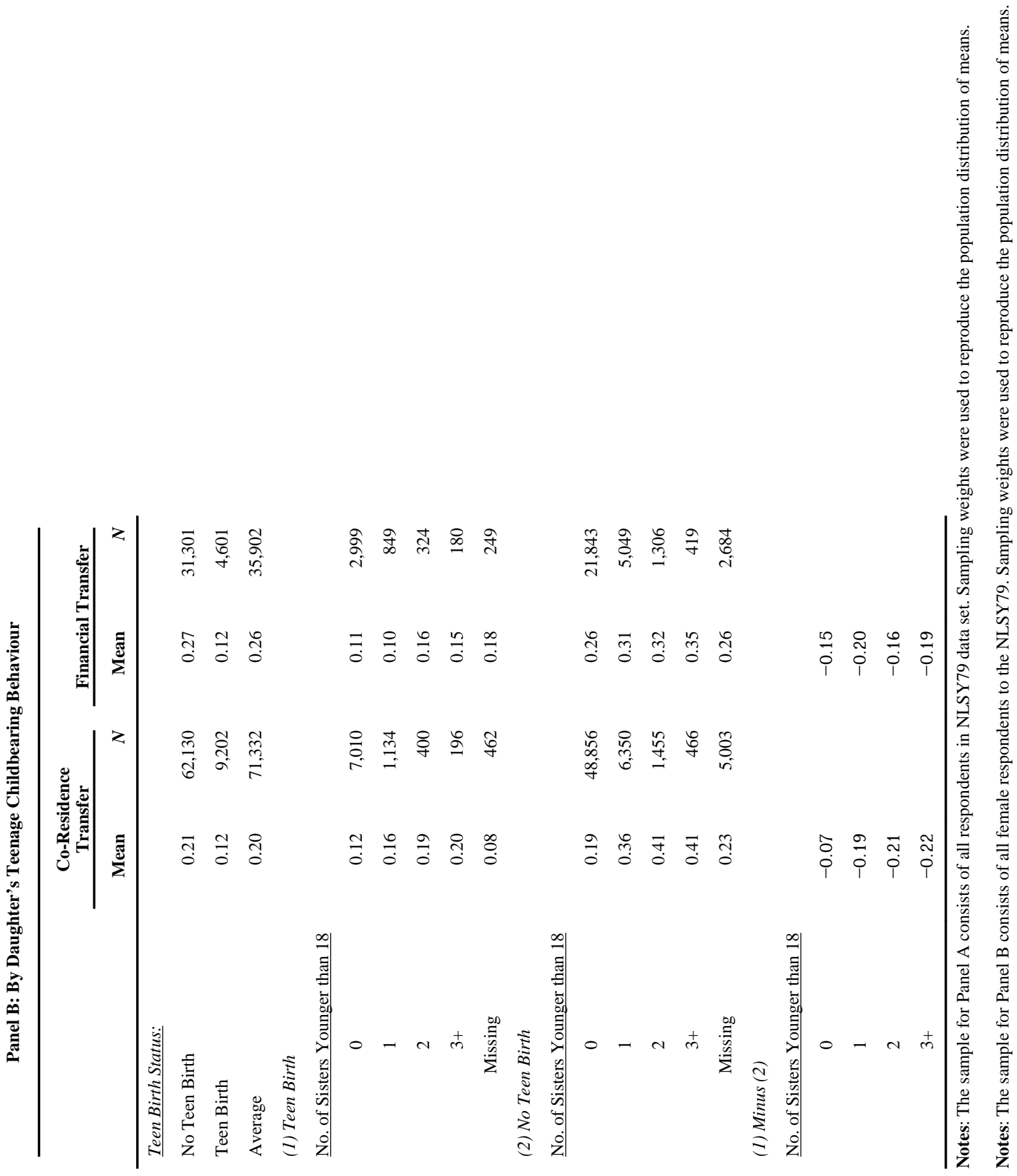


Table 2

Offspring's Risky Behaviours by Number of Offspring (Daughters)

\begin{tabular}{cccccr}
\hline & \multicolumn{2}{c}{$\begin{array}{c}\text { High School } \\
\text { Dropout }\end{array}$} & & \multicolumn{2}{c}{ Teen Birth } \\
\cline { 2 - 3 } & Mean & $N$ & & Mean & $N$ \\
\hline \multicolumn{3}{c}{ Panel A. All Offspring (Daughters) Sample } \\
0 & 0.22 & 3,503 & & 0.08 & 2,591 \\
1 & 0.21 & 2,540 & & 0.08 & 1,237 \\
2 & 0.25 & 1,536 & & 0.12 & 467 \\
$3+$ & 0.34 & 1,397 & & 0.17 & 228 \\
Missing & 0.25 & 2,352 & & 0.05 & 392 \\
Total & 0.24 & 11,328 & & 0.09 & 4,915
\end{tabular}

Panel B. Multiple Offspring per Family (Daughters) Subsample

\begin{tabular}{crrrr}
0 & 0.20 & 1,497 & 0.07 & 568 \\
1 & 0.18 & 1,501 & 0.07 & 500 \\
2 & 0.21 & 944 & 0.06 & 237 \\
$3+$ & 0.30 & 848 & 0.14 & 95 \\
Missing & 0.22 & 669 & 0.01 & 111 \\
Total & 0.21 & 5,459 & 0.07 & 1,511 \\
\hline
\end{tabular}

Notes: Samples for High School Dropout behaviour consist of all respondents in the NLSY79 data (All Offspring) and the subsample of respondents that had at least one sibling in the NLSY79 data (Multiple Offspring per Family).

Samples for Teenage Childbearing behaviour consist of all female respondents in the NLSY79 data (All Daughters) and the subsample of female respondents that had more than one sister in the NLSY79 data set (Multiple Daughters per Family).

Sampling weights were used to reproduce the population distribution of means. 


\section{Table 3}

Estimates of Parental Transfer Response Equations

\begin{tabular}{|c|c|c|c|c|}
\hline \multirow{2}{*}{ Variable } & \multicolumn{2}{|c|}{ Co-Residence Transfer } & \multicolumn{2}{|c|}{ Financial Transfer } \\
\hline & (1) & (2) & (1) & (2) \\
\hline \multicolumn{5}{|c|}{ Panel A. As Function of Offspring's High School Dropout Status } \\
\hline \multirow[t]{2}{*}{ No. of Siblings Younger than $18(N Y G)$} & $0.0175^{* * *}$ & 0.0049 & $0.0075^{*}$ & -0.0079 \\
\hline & $(0.0024)$ & $(0.0035)$ & $(0.0040)$ & $(0.0060)$ \\
\hline \multirow[t]{2}{*}{ HS Dropout $\times$ No. of Siblings Younger than $18(B \times N Y G)$} & -0.0446 **** & $-0.0432^{* * *}$ & $-0.0556^{* * * *}$ & $-0.0529^{* * *}$ \\
\hline & $(0.0033)$ & $(0.0036)$ & $(0.0058)$ & $(0.0059)$ \\
\hline \multirow[t]{2}{*}{ Age Gap with Next Oldest Sibling ( $A G A P)$} & & $-0.0038^{* * * *}$ & & -0.0021 \\
\hline & & $(0.0009)$ & & $(0.0015)$ \\
\hline \multirow[t]{2}{*}{ High School Dropout $\times$ Age Gap of Siblings $(B \times G A P)$} & & 0.0001 & & 0.0001 \\
\hline & & $(0.0008)$ & & $(0.0015)$ \\
\hline Number of Person-Years & 144,758 & 144,758 & 73,242 & 73,242 \\
\hline Number of Individuals & 11,269 & 11,269 & 11,184 & 11,184 \\
\hline$R^{2}$ for within-individual variation & 0.23 & 0.23 & 0.11 & 0.11 \\
\hline \multicolumn{5}{|c|}{ Panel B. As Function of Daughter's Teenage Childbearing Status } \\
\hline \multirow[t]{2}{*}{ No. of Sisters Younger than $18(N Y G)$} & $0.0264^{* * *}$ & $0.0252^{* * *}$ & $0.0210^{* * *}$ & $0.0289^{* *}$ \\
\hline & $(0.0040)$ & $(0.0073)$ & $(0.0072)$ & $(0.0131)$ \\
\hline \multirow[t]{2}{*}{ Teen Birth $\times$ No. of Sisters Younger than $18(B \times N Y G)$} & $-0.0953^{* * * *}$ & $-0.1063^{* * *}$ & $-0.1027^{* * *}$ & $-0.1027^{* * *}$ \\
\hline & $(0.0079)$ & $(0.0092)$ & $(0.0148)$ & $(0.0153)$ \\
\hline \multirow[t]{2}{*}{ Age Gap with Next Oldest Sister (AGAP) } & & $-0.0055^{* * *}$ & & 0.0039 \\
\hline & & $(0.0013)$ & & $(0.0025)$ \\
\hline \multirow[t]{2}{*}{ Teen Birth $\times$ Age Gap of Sisters $(B \times A G A P)$} & & $0.0041^{* *}$ & & -0.0004 \\
\hline & & $(0.0017)$ & & $(0.0031)$ \\
\hline Number of Person-Years & 71,332 & 71,332 & 35,902 & 35,902 \\
\hline Number of Individuals & 4,908 & 4,908 & 4,878 & 4,878 \\
\hline$R^{2}$ for within-individual variation & 0.28 & 0.28 & 0.14 & 0.14 \\
\hline
\end{tabular}

Notes: The sample for Panel A consists of all respondents in NLSY79 data set while the sample for Panel B consists of all female respondents to the NLSY79.

Measurement of dependent Variables: Co-Residence Transfer $=1$ if the respondent lives with parents, $=0$ otherwise. Financial transfer $=1$ if parents provide at least half of living expenses, $=0$ otherwise.

$* p<0.10 ;$
$* * \quad p<0.05 ;$
$\quad * * * \quad p<0.01$ 


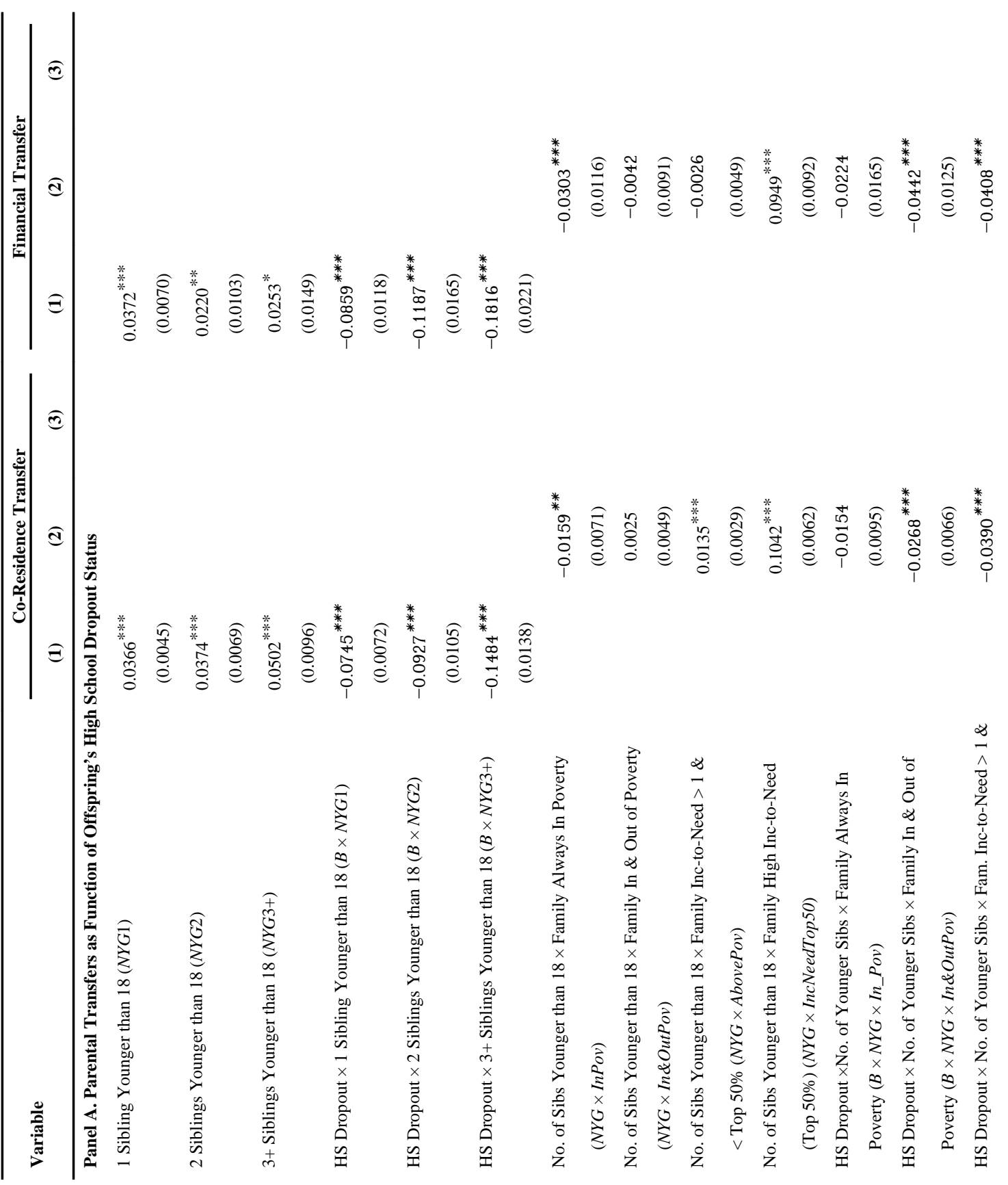


Hao et al.

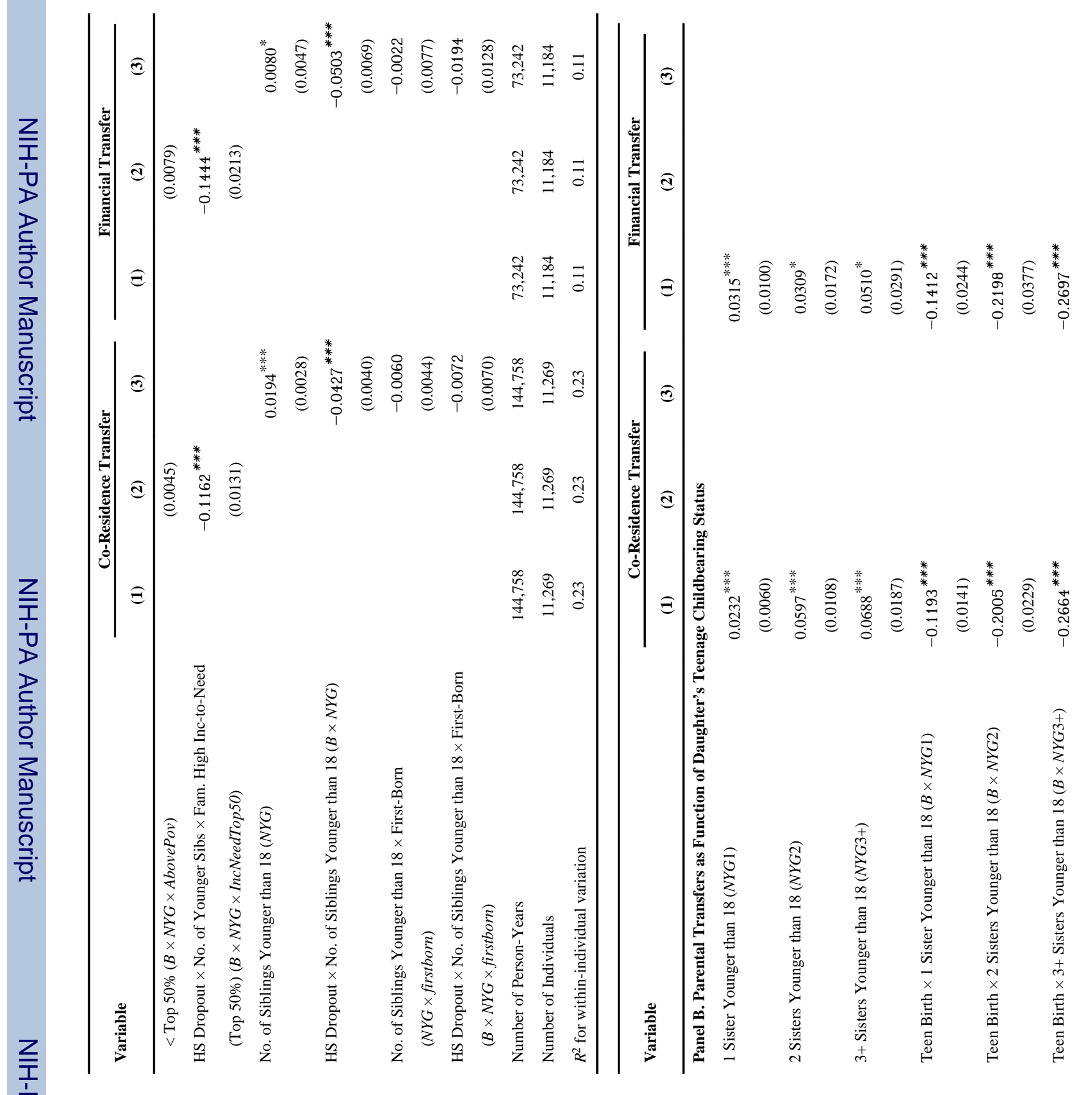

Econ J (London). Author manuscript; available in PMC 2011 June 7. 


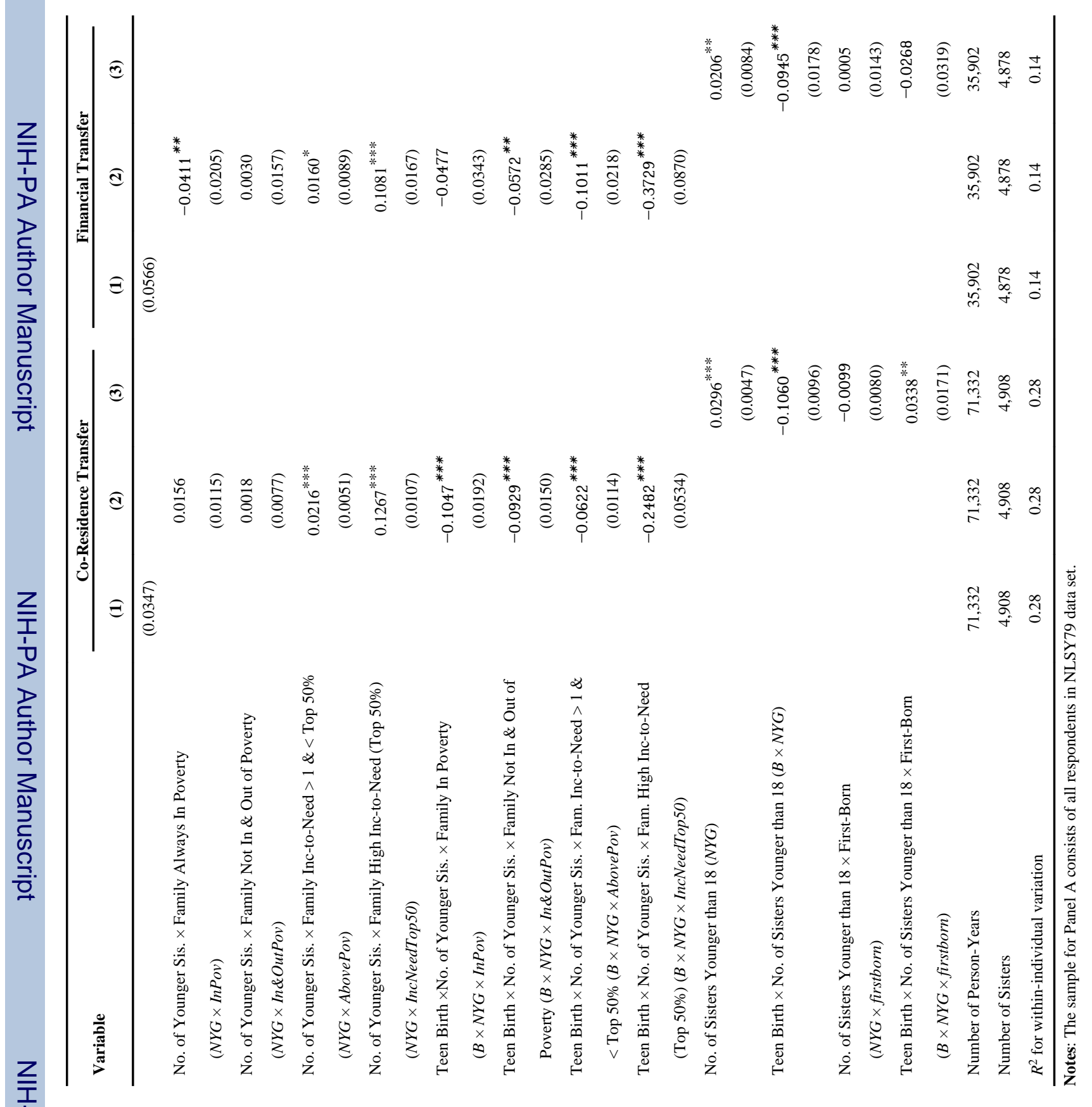


Hao et al.

Page 37

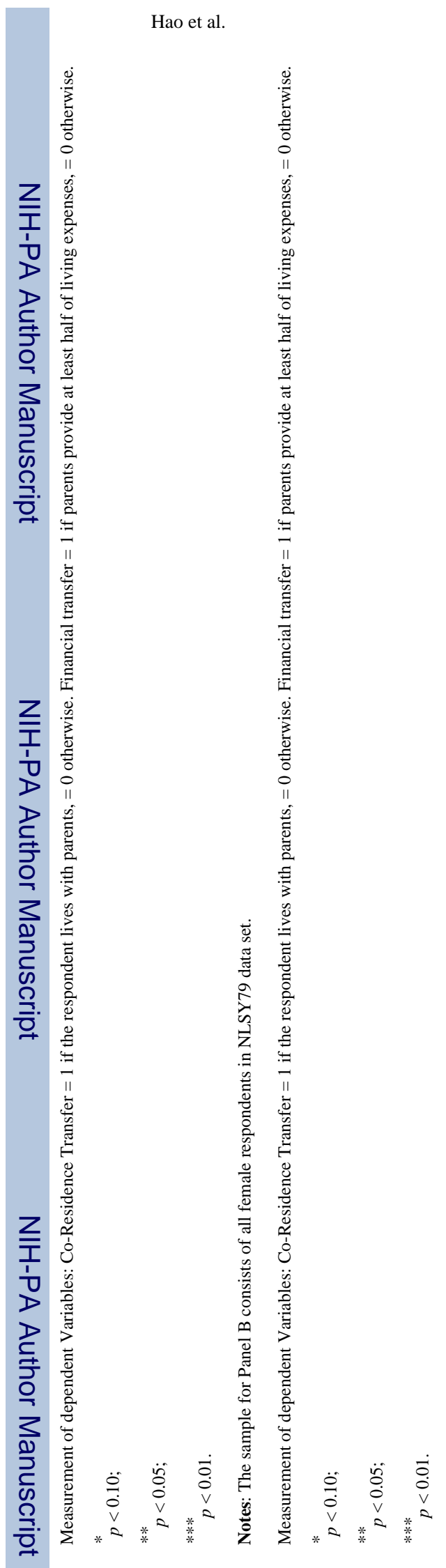

Econ J (London). Author manuscript; available in PMC 2011 June 7. 
Table 5

Estimates of Offspring Risk-Taking Behaviour Equations

\begin{tabular}{lcc}
\hline Variable & (1) & $(\mathbf{2})$ \\
\hline Panel A. Offspring's High School Dropout Decision & \\
No. of Siblings Younger than $18(N Y G)$ & $-0.0295^{* * * *}$ & $-0.0322^{* * *}$ \\
& $(0.0100)$ & $(0.0113)$ \\
Age Gap with Next Oldest Sibling $(A G A P)$ & & -0.0031 \\
& & $(0.0045)$ \\
Number of Offspring & 5,459 & 5,459 \\
Number of Families & 2,283 & 2,283 \\
$R^{2}$ for within-family variation & 0.06 & 0.06 \\
Panel B. Daughter's Teenage Childbearing Decision & \\
No. of Sisters Younger Than $18(N Y G)$ & -0.0170 & -0.0148 \\
& $(0.0191)$ & $(0.0234)$ \\
Age Gap with Next Oldest Sister $(A G A P)$ & & -0.0008 \\
& & $(0.0054)$ \\
$R^{2}$ for within-family variation & 1,511 & 1,511 \\
\hline
\end{tabular}

Notes: The sample for Panel A consists of respondents that had at least one sibling in the NLSY79 data.

The sample for Panel B consists of female respondents that had at least one sister in the NLSY79 data.

$p<0.10$

** $p<0.05$;

**** $p<0.01$ 
Table 6

Robustness Checks for Offspring Risk-Taking Behaviour Equations

\begin{tabular}{|c|c|c|c|}
\hline Variable & (1) & (2) & (3) \\
\hline \multicolumn{4}{|l|}{ Panel A. Offspring's High School Dropout Decision } \\
\hline \multirow[t]{2}{*}{1 Sibling Younger than $18(N Y G 1)$} & -0.0281 & & \\
\hline & $(0.0211)$ & & \\
\hline \multirow[t]{2}{*}{2 Siblings Younger than 18 (NYG2) } & -0.0218 & & \\
\hline & $(0.0289)$ & & \\
\hline \multirow[t]{2}{*}{ 3+ Siblings Younger than $18(N Y G 3+)$} & $-0.1060^{* * *}$ & & \\
\hline & $(0.0363)$ & & \\
\hline No. of Sibs Younger than $18 \times$ Family Always In Poverty & & $-0.0416^{*}$ & \\
\hline$(N Y G \times I n P o v)$ & & $(0.0246)$ & \\
\hline No. of Sibs Younger than $18 \times$ Family In \& Out of Poverty & & $-0.0386^{*}$ & \\
\hline$(N Y G \times \operatorname{In} \& O u t P o v)$ & & $(0.0231)$ & \\
\hline No. of Sibs Younger than $18 \times$ Family Inc-to-Need $>1 \&$ & & $-0.0316^{* *}$ & \\
\hline$<$ Top $50 \%(N Y G \times$ AbovePov $)$ & & $(0.0123)$ & \\
\hline No. of Sibs Younger than $18 \times$ Family High Inc-to-Need & & $-0.0364^{*}$ & \\
\hline$($ Top $50 \%)(N Y G \times$ IncNeedTop 50$)$ & & $(0.0206)$ & \\
\hline \multirow[t]{2}{*}{ No. of Siblings Younger than $18(N Y G)$} & & & $-0.0333^{* * *}$ \\
\hline & & & $(0.0105)$ \\
\hline \multirow[t]{2}{*}{ First-Born Child (firstborn) } & & & -0.0447 \\
\hline & & & $(0.0287)$ \\
\hline No. of Siblings Younger than $18 \times$ First-Born Child & & & 0.0188 \\
\hline$(N Y G \times$ firstborn $)$ & & & $(0.0116)$ \\
\hline Number of Offspring & 5,459 & 5,459 & 5,459 \\
\hline Number of Families & 2,283 & 2,283 & 2,283 \\
\hline$R^{2}$ for within-family variation & 0.06 & 0.06 & 0.06 \\
\hline \multicolumn{4}{|l|}{ Panel B. Daughter's Teenage Childbearing Decision } \\
\hline \multirow[t]{2}{*}{1 Sisters Younger than $18(N Y G 1)$} & -0.0197 & & \\
\hline & $(0.0256)$ & & \\
\hline \multirow[t]{2}{*}{2 Sisters Younger than $18(N Y G 2)$} & -0.0603 & & \\
\hline & $(0.0428)$ & & \\
\hline \multirow[t]{2}{*}{$3+$ Sisters Younger than $18(N Y G 3+)$} & -0.0108 & & \\
\hline & $(0.0631)$ & & \\
\hline No. of Sis Younger than $18 \times$ Family Always In Poverty & & -0.0468 & \\
\hline$(N Y G \times \operatorname{InPov})$ & & $(0.0437)$ & \\
\hline No. of Sis Younger than $18 \times$ Family In $\&$ Out of Poverty & & -0.0023 & \\
\hline$(N Y G \times \operatorname{In} \& O u t P o v)$ & & $(0.0451)$ & \\
\hline No. of Sis Younger than $18 \times$ Family Inc-to-Need $>1 \&$ & & -0.0206 & \\
\hline$<$ Top $50 \%(N Y G \times$ AbovePov $)$ & & $(0.0221)$ & \\
\hline No. of Sis Younger than $18 \times$ Family High Inc-to-Need & & $-0.0652^{* *}$ & \\
\hline
\end{tabular}




\begin{tabular}{lccc}
\hline Variable & $\mathbf{( 1 )}$ & $\mathbf{( 2 )}$ & $(\mathbf{3})$ \\
\hline $\begin{array}{l}\text { Top 50\%) }(\text { NYG } \times \text { IncNeedTop50) } \\
\text { No. of Sisters Younger than } 18(N Y G)\end{array}$ & & $(0.0310)$ & \\
& & -0.0230 \\
First-Born Child (firstborn) & & $(0.0199)$ \\
& & -0.0175 \\
No. of Sisters Younger than 18 $\times$ First-Born & & $(0.0385)$ \\
$\quad$ NYG $\times$ firstborn $)$ & & & 0.0225 \\
Number of Daughters & 1,511 & 1,511 & 1,511 \\
Number of Families & 691 & 691 & 691 \\
$R^{2}$ for within-family variation & 0.23 & 0.24 & 0.23 \\
\hline
\end{tabular}

Notes: The sample for Panel A consists of respondents that had at least one sibling in the NLSY79 data.+

The sample for Panel B consists of female respondents that had at least one sister in the NLSY79 data.

* $p<0.10$

** $p<0.05$;

*** $p<0.01$. 


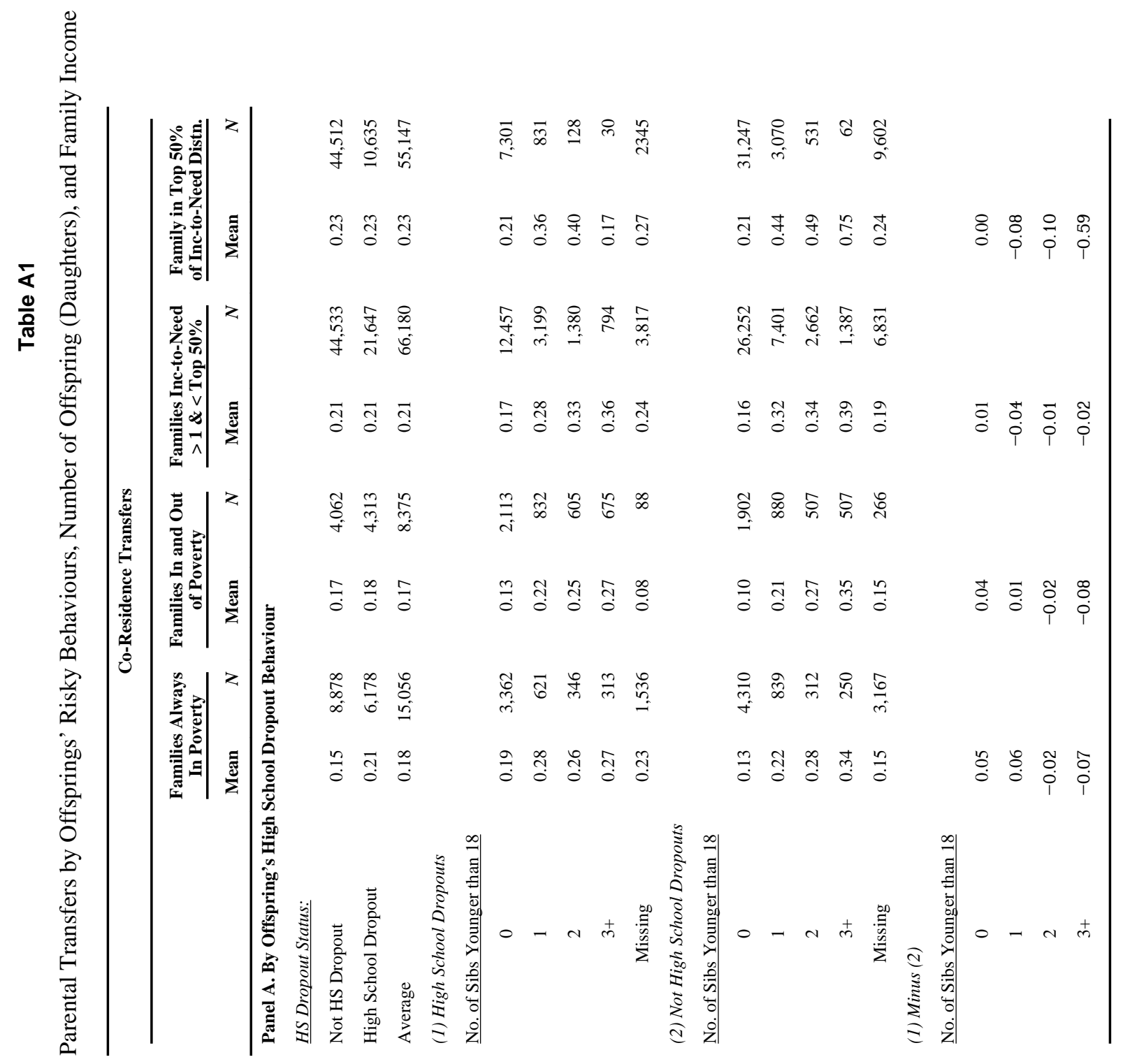


Hao et al.

Page 42

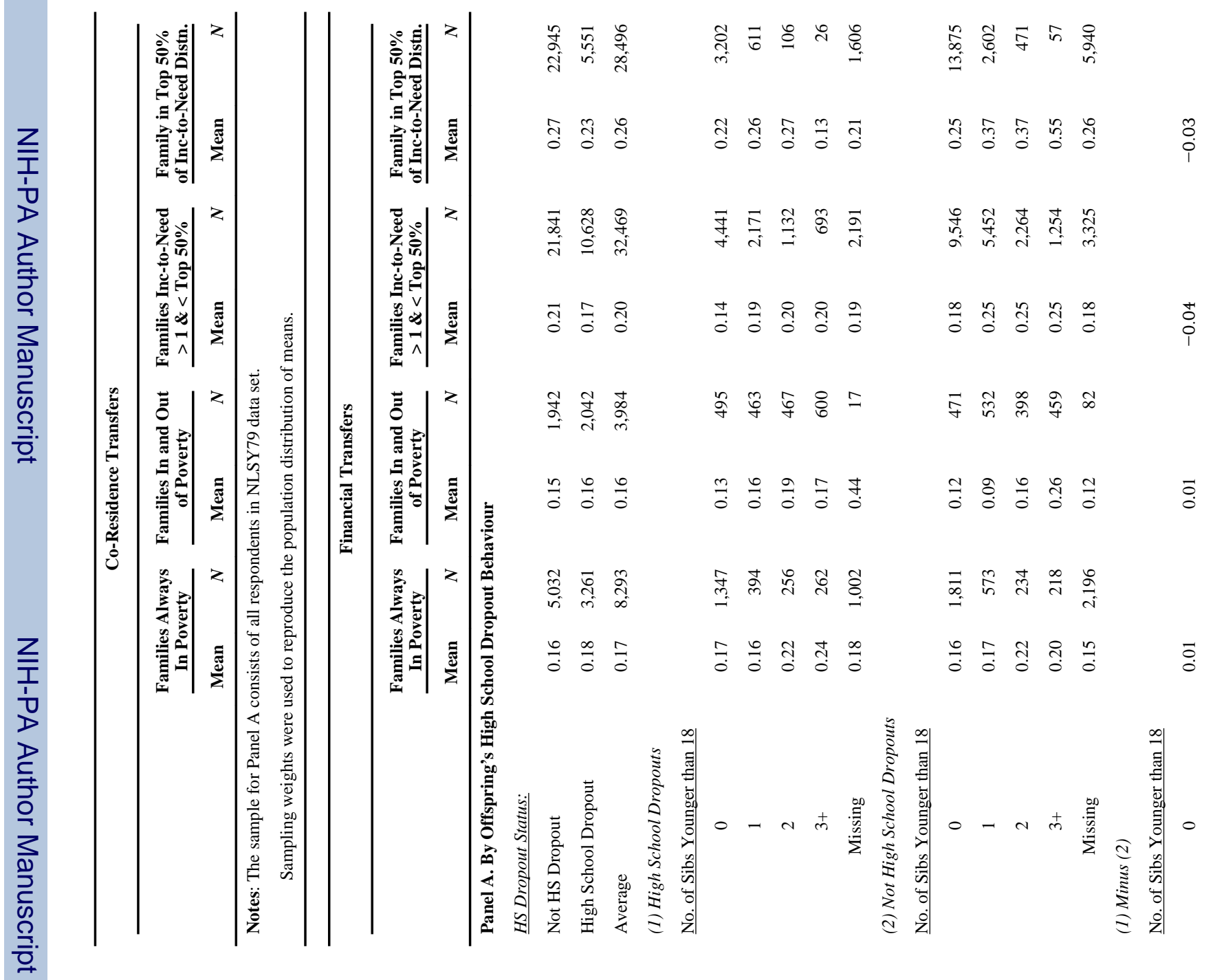

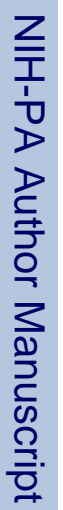

Econ J (London). Author manuscript; available in PMC 2011 June 7. 


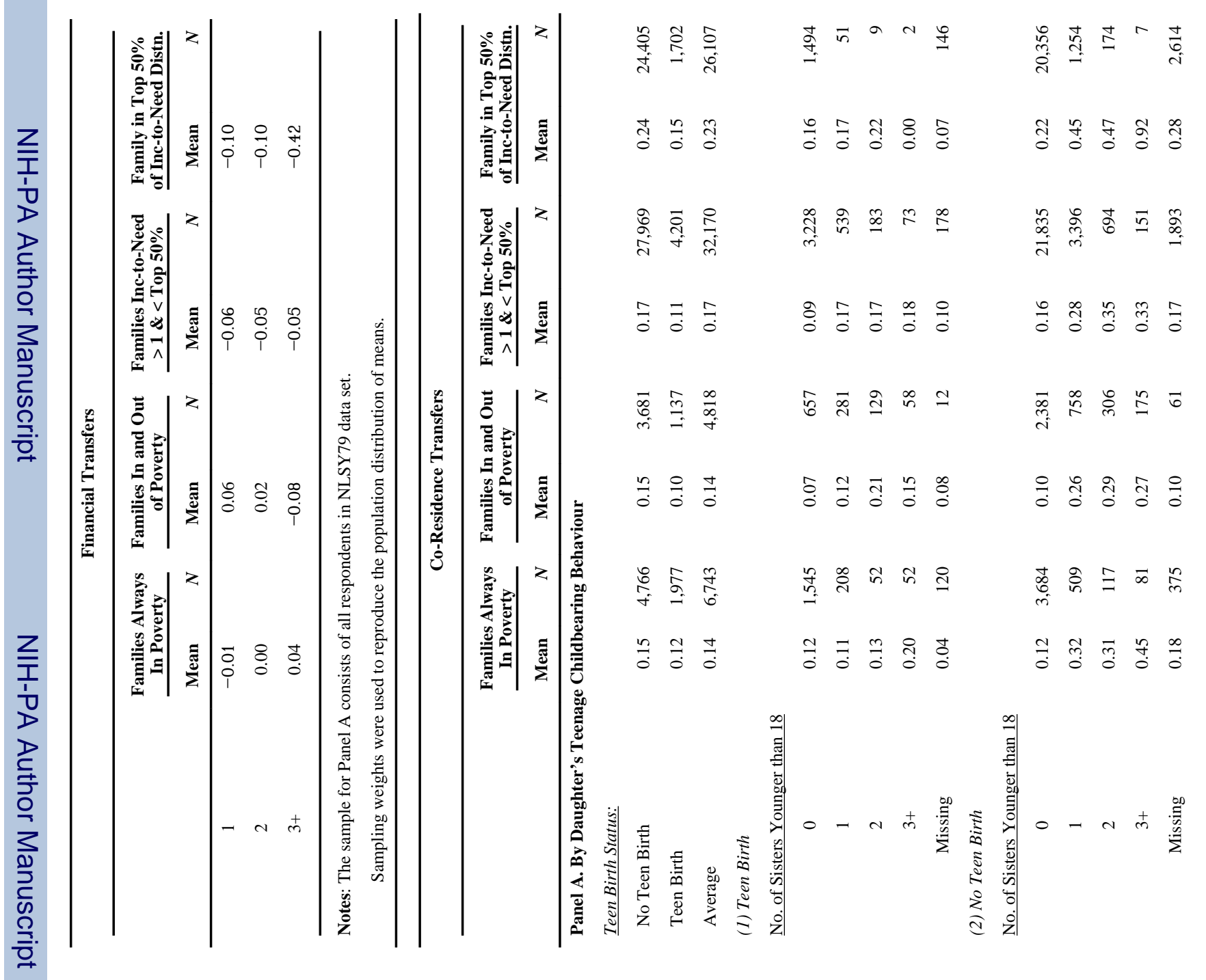


Hao et al.

Page 44

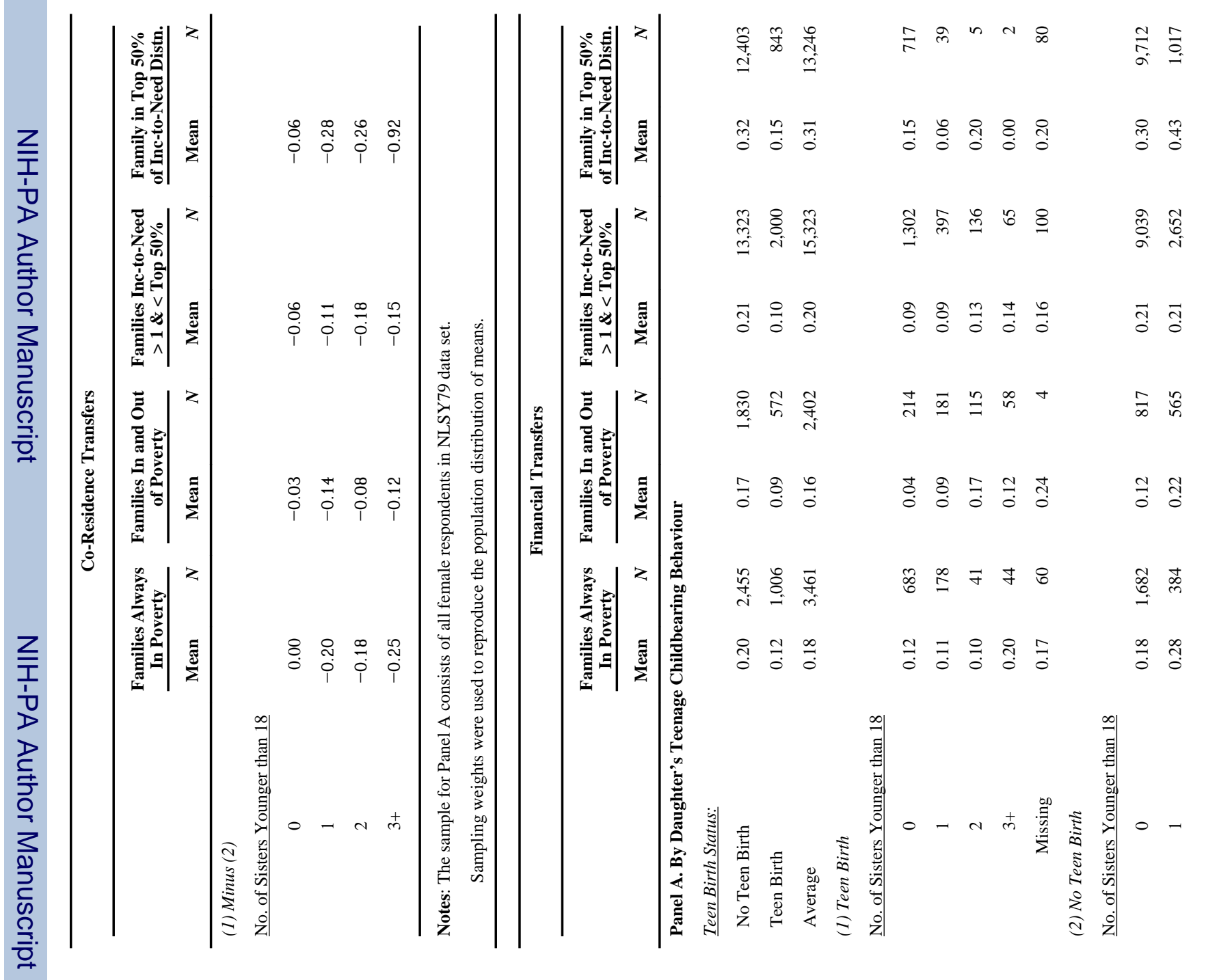

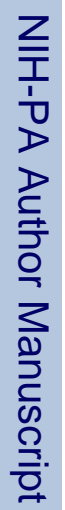

Econ J (London). Author manuscript; available in PMC 2011 June 7. 


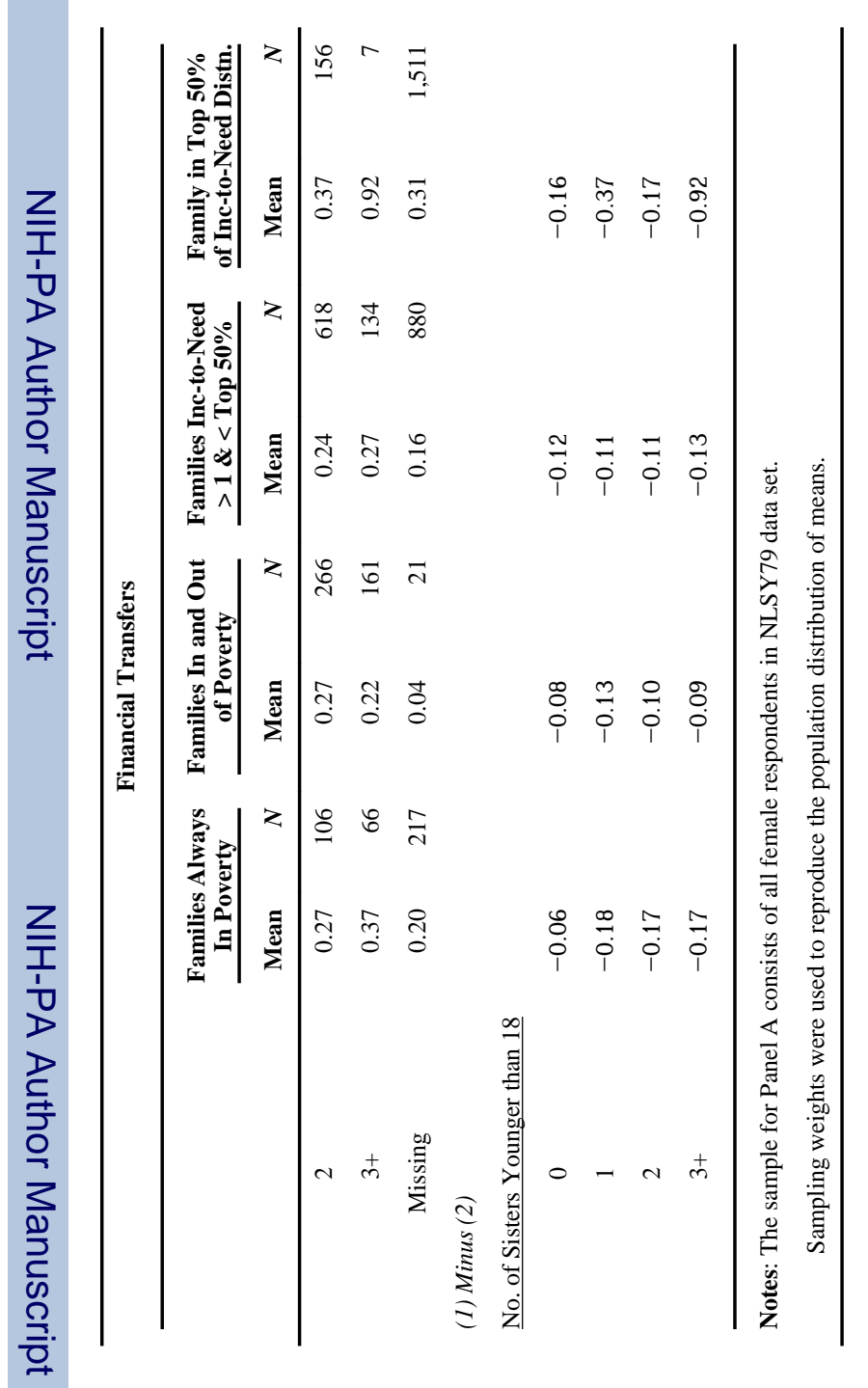

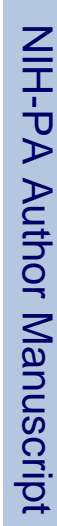




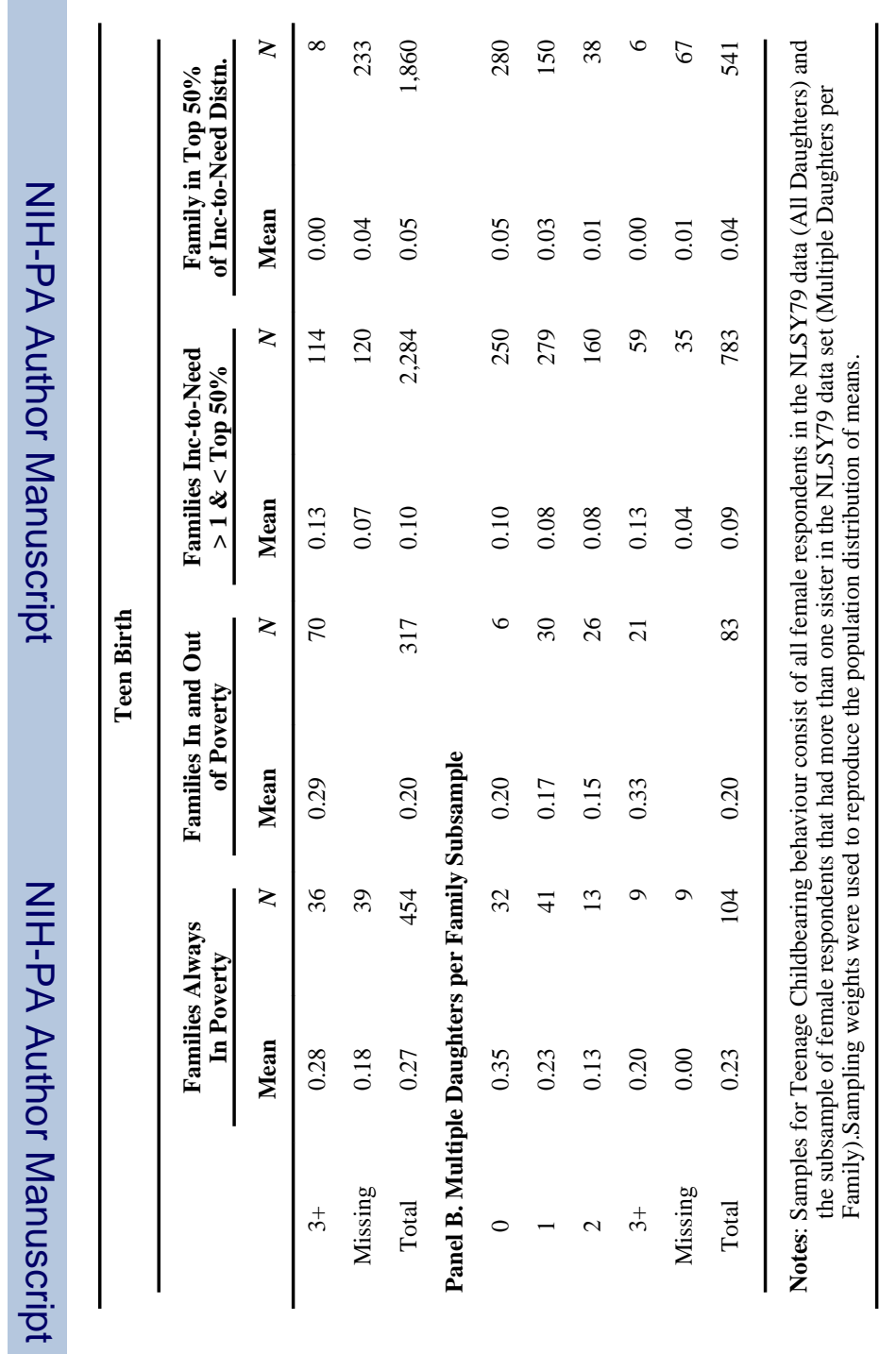

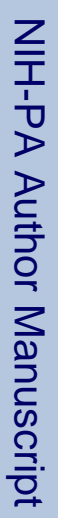

